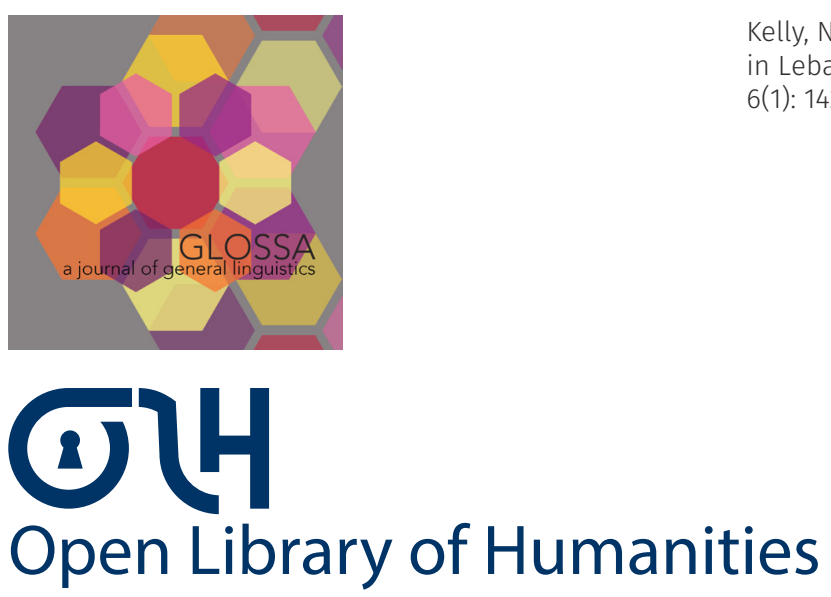

E. 2021. Syllable weight, vowel length and focus Lebanese Arabic. Glossa: a journal of general linguistics 6(1): 142, pp. 1-31. DOI: https://doi.org/10.16995/glossa.5727

\title{
Syllable weight, vowel length and focus in Lebanese Arabic
}

Niamh E. Kelly, University of Texas at El Paso, US, nekelly@utep.edu

Research on a variety of languages has shown that vowel duration is influenced by phonological vowel length as well as syllable structure (e.g., Maddieson 1997). Further, the phonological concept of a mora has been shown to relate to phonetic measurements of duration (Port, Dalby, \& O'Dell 1987; Hubbard 1993; Cohn 2003). In Levantine Arabic, non-final closed syllables that contain a long vowel have been described as partaking in mora-sharing (Broselow, Chen, \& Huffman 1997; Khattab \& Al-Tamimi 2014). The current investigation examines the effect of vowel length and syllable structure on vowel duration, as well as how this interacts with durational effects of prosodic focus. Disyllabic words with initial, stressed syllables that were either open or closed and contained either a long or a short vowel were examined when non-focused and in contrastive focus. Contrastive focus was associated with longer words, stressed syllables and phonologically long vowels. Short vowels were shorter when in a syllable closed by a singleton but not by a geminate consonant, while long vowels were not shortened before coda singletons. An analysis is proposed whereby long vowels followed by an intervocalic consonant cluster are parsed as open syllables, with the first consonant forming a semisyllable (Kiparsky 2003), while long vowels followed by geminate consonants partake in mora-sharing (Broselow, Huffman, Chen, \& Hsieh 1995). The results also indicate compensatory shortening for short vowels followed by a singleton coda.

Glossa: a journal of general linguistics is a peer-reviewed open access journal published by the Open Library of Humanities. (c) 2021 The Author(s). This is an open-access article distributed under the terms of the Creative Commons Attribution 4.0 International License (CC-BY 4.0), which permits unrestricted use, distribution, and reproduction in any medium, provided the original author and source are credited. See http://creativecommons.org/licenses/by/4.0/. 


\section{Introduction}

The current investigation examines segments in Lebanese Arabic to determine the phonetic effects of syllable structure as well as to illuminate phonological theories of mora-sharing. Since syllables closed by geminate consonants have been the subject of most previous quantitative work, a particular focus of the current work is non-final syllables that are closed by a singleton consonant. The effect of contrastive focus on the duration of long and short segments is also examined, since this has not been examined in Lebanese Arabic before, and work on other languages with phonological vowel length has demonstrated an interaction between vowel length and lengthening under focus (Bruce 1977; Kelly \& Smiljanić 2017).

\subsection{Vowel length, syllable structure and weight}

It is well established that phonemic vowel length is expressed through vowel duration (e.g., (Jongman 1998; Hall 2017). For example, in an examination of Dutch, Jongman (1998) found that long vowels had twice the duration of short vowels. The actual duration ratios between phonologically long and short vowels varies by language and language variety, for example, Jordanian Arabic was found to have long vowels that were 120\% longer than short vowels (de Jong \& Zawaydeh 2002). Cross-linguistically, a variety of phonetic effects have also been found to influence vowel duration, for example, vowels tend to be longer when they are in open syllables than in closed syllables (Maddieson 1997). One such example is in Palestinian Arabic, where there is a pattern of closed-syllable shortening of phonologically long vowels when in CV:CC syllables (Hall 2017). It has also been established that vowels tend to be longer before voiced than voiceless consonants (House \& Fairbanks 1953; Peterson \& Lehiste 1960; House 1961), although this has been shown not to be universal; speakers of Jordanian Arabic did not produce a difference in vowel duration based on the voicing of the following consonant (Mitleb 1984).

Research on syllable structure and phonological length is intertwined with moraic theory (Hyman 1985; McCarthy \& Prince 1986; Hayes 1989), where syllable weight is measured in moras. ${ }^{1}$ In this theory, light syllables, such as CV, count as one mora and heavy syllables, such as CVV, count as two, or are bimoraic, while onsets are generally considered not to bear weight. (However, some research has shown that onsets can bear weight and contribute to stress assignment (Gordon 2005; Ryan 2014; Mai 2020)). What counts as a mora is language-dependent, and analyses of what types of syllables are considered to be heavy are often based on an examination of weight-sensitive stess patterns. Some languages count CVC as light because the coda C does

\footnotetext{
${ }^{1}$ While the current investigation focuses on moraic theory, it must be noted that other syllable structure theories exist, including for example, the Strict CV approach (Lowenstamm 1996; Scheer 2004), which states that all syllables can be expressed as a flat CV structure.
} 
not have a mora, such as Malayalam (Broselow et al. 1997), and some count CVC as heavy, such as Latin. For yet other languages, the weight of CVC depends on the type of $\mathrm{C}$, for example, in Lithuanian, CVC is light if the final C is an obstruent, and heavy if it is a sonorant (Kenstowicz 1970; Blevins 1993). Some languages (such as Hindi) allow trimoraic, superheavy syllables such as CVVC or CVCC (Broselow et al. 1997; Gordon 2002). (Gordon (2002) describes syllable weight as a complex interplay of phonetics and phonology, where languages "choose weight distinctions that divide syllables into two groups of maximally differentiated syllables along the phonetic/ perceptual parameter of total energy" (p.76). He also notes that phonetic patterns alone cannot fully explain phonological weight patterns, because languages do not make use of patterns that would be phonetically effective but are overly complex in terms of phonology. The phonological concept of a mora has been shown to relate to phonetic measurements of duration (Port et al. 1987; Hubbard 1993; Cohn 2003), for example, in compensatory lengthening in Latin (Hayes 1989), rime duration in Hungarian (Ham 1998; Cohn 2003) as well as whether a coda consonant counts as a mora or not in Malayalam, Hindi and Arabic (Broselow et al. 1997) (discussed further in section 1.1.1).

\subsubsection{Syllables in Arabic}

Arabic is in the Semitic language family, and the dialects are split into several branches, with Lebanese, Palestinian, Syrian and Jordanian in the Levantine branch (e.g., Versteegh 1997). Research into Lebanese Arabic phonology has a long history (Nasr 1959; Obégi 1971; AbdulKarim 1980; Makki 1983; Haddad 1984), continuing into the present day (Hall 2013; Khattab \& Al-Tamimi 2014; Sakr 2019). Arabic has a length contrast in both consonants and vowels (Nasr 1960). In Levantine Arabic, it has been noted that duration is a reliable cue for distinguishing long and short vowels (Hall 2017) as well as singleton and geminate consonants (Khattab \& Al-Tamimi 2014).

Arabic does not allow onsetless syllables (Kiparsky 2003), and this includes Lebanese Arabic (Haddad 1984). In his description of syllable onsets in Lebanese Arabic, Obégi (1971) notes that any consonant can constitute an onset. Onsets can be complex (CC) but the two consonants must agree in pharyngealization. Initial geminates can arise from assimilation (Kiparsky 2003), and Makki (1983) also notes that many consonants can occur as geminates in initial position, although they always arise through morphological prefixation or assimilation.

Possible rime types in Arabic include V, VC, VV, VVC and VCC, while VVGG (with GG for geminate) also occurs but only in word-final position (Bamakhramah 2009; Watson 2011). In Arabic, stress assignment is determined by syllable weight. Lexical stress in Lebanese Arabic is described as falling on: a word-final superheavy syllable, then on a heavy penult, then for disyllabic words ending in CV or CVC, on the initial syllable, and otherwise on the antepenult, whether heavy or light (McCarthy 1979; Abdul-Karim 1980; Chahal 2001; Watson 2011). In 
final position, CVVC has been analyzed as the final C being extrametrical (Watson 2011). In an analysis of syllable weight in non-final syllables, Broselow et al. (1997) conclude that in Levantine Arabic, a coda C has a mora in CVC but is weightless in CVVC, so both syllable types are considered bimoraic. VVC and VCC rimes are also described as bimoraic by Abu-Salim and Abdel-Jawad (1988), at least in Levantine Arabic (Bamakhramah 2009), due to mora-sharing (Broselow 1992; Broselow et al. 1995; 1997; Watson 2007). As Watson (2007) notes, this concept was proposed based on previous work on degenerate syllables in Arabic by Aoun (1979) and Selkirk (1981). In an examination of one speaker each of Jordanian Arabic (Broselow et al. 1997), and Syrian and Lebanese Arabic (Broselow et al. 1995), measures of duration support their analysis that the coda $\mathrm{C}$ is sharing a mora with the vowel in CVVC because long vowels in CVVC are shorter than those in CVV. The presence of a coda consonant in syllables with a short vowel has no effect on vowel duration, because the $\mathrm{C}$ has its own mora. Finally, coda $\mathrm{C}$ in CVVC tends to be shorter than in CVC, because in the former it is sharing a mora, rather than having its own mora. The mora-based representations of these are shown in Figure 1.

Watson (2007) proposes that mora-sharing is allowed in order to avoid trimoraic syllables, and that in Levantine Arabic, mora-sharing is only permissible when the syllable rime contains a long vowel. Broselow et al. (1997) state that CVCC is restricted in its occurrence, while Bamakhramah (2009) describes CVCC also in terms of mora-sharing, where the first C in the coda bears weight but the second one shares a mora. By these analyses, syllables that would be superheavy (trimoraic), surface as bimoraic due to this pattern of mora-sharing. Kiparsky (2003) divides Arabic dialects into VC-, CV- and C-dialects, based on licit patterns of consonant clusters, including how triconsonantal clusters are resyllabified by vowel insertion. Lebanese Arabic is considered a VC-dialect, meaning that in a word-medial CCC cluster, an epenthetic vowel is added between the first two consonants, leaving CiCC. While Watson (2007) proposes mora-sharing, Kiparsky (2003) proposes an explanation by way of semisyllables (Figure 2), which are moras

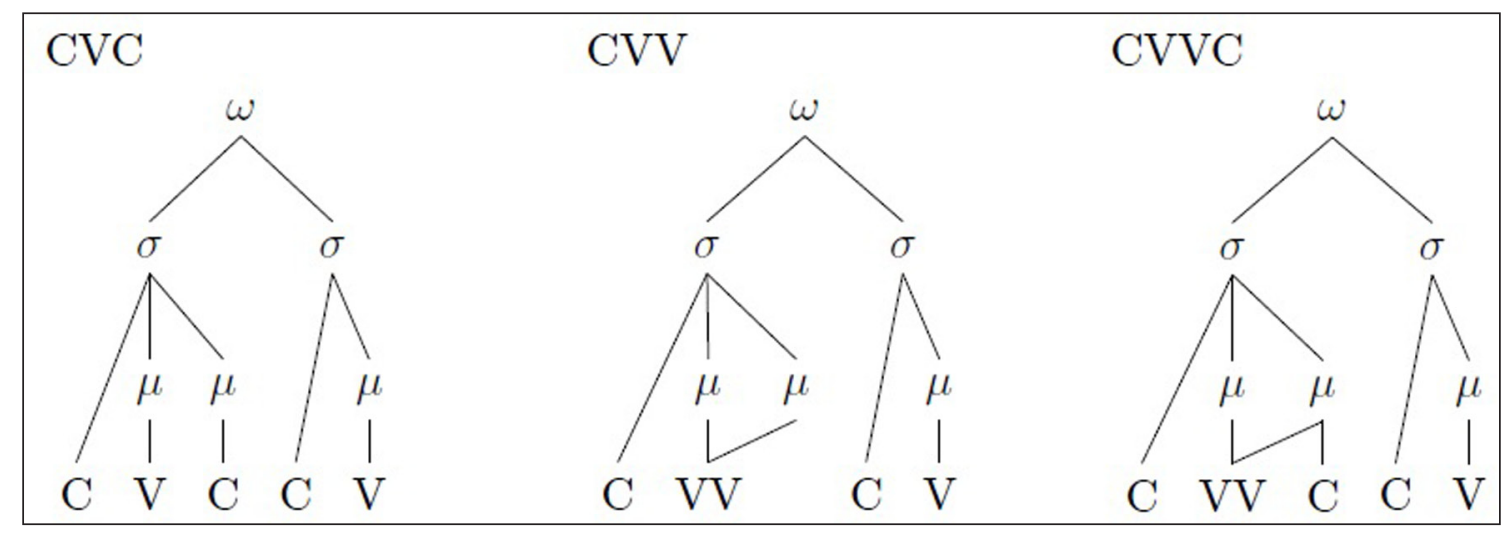

Figure 1: Mora-based representation of non-final CVC, CVV and CVVC. 


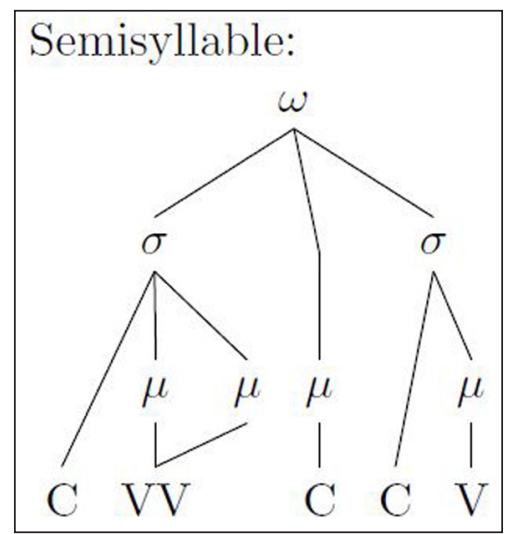

Figure 2: Semisyllable analysis (Kiparsky 2003).

that are "prosodically licensed by adjunction to a superordinate prosodic category" (p.154). This analysis states that VC-dialects (which include Lebanese Arabic) would not shorten a long vowel in non-final CVVC because the $\mathrm{C}$ is instead a semisyllable, meaning that it weighs a mora but it is not part of the same syllable as the preceding vowel. Watson (2007) responded to this analysis, updating the description of VC-dialects to add that not only do they allow semisyllables at the word level, as proposed by Kiparsky, but also that mora-sharing is "permitted iff the syllable contains a long vowel" (p.354).

Geminate consonants in Arabic have generally been analyzed as being linked to a single mora (Abu-Salim \& Abdel-Jawad 1988; Bamakhramah 2009; Davis \& Ragheb 2014), meaning that when they are in word-medial (intervocalic) position, they are weightless as the onset of the second syllable but weigh one mora as the coda of the first syllable (Hayes 1989; Khattab \& Al-Tamimi 2014). In Jordanian Arabic, Al-Tamimi (2004) found that intervocalic geminate consonants were two to three times longer than their singleton counterparts. This study also found that both long and short vowels were shorter before geminate consonants than singleton consonants, and Al-Tamimi notes that these findings are not only language-specific but variety-specific, because this pattern was not found for Iraqi Arabic. This is corroborated by an examination of Lebanese Arabic, where only phonologically long vowels were found to be shortened before intervocalic geminates, while short vowels were not affected (Khattab \& Al-Tamimi 2014). The authors also found an effect of whether the vowel was followed by a geminate or singleton consonant, with the ratio of the duration of short to long vowels at 1:2.1 before singleton consonants (which constituted the onset of the following syllable) and 1:1.91 before geminate consonants. Geminate consonants were also found to be twice as long as singleton consonants.

While a large-scale analysis of vowels preceding intervocalic geminates in Lebanese Arabic has shown conclusively that long vowels are shortened while short vowels are not (Khattab \& Al-Tamimi 2014), the only work examing this question for intervocalic non-geminate clusters 
was a very small-scale study (Broselow et al. 1997). One aim of the current study is to test these findings on a larger scale.

\subsection{Focus and its effects on duration}

Phonemic length and phonetic factors relating to segments and syllable structure are not the only effects on segment duration. It has also been shown that prosodic factors, including focus, have effects on segments (e.g., Pierrehumbert 1980; Cooper, Eady \& Mueller 1985; Xu \& Xu 2005).

In information structure, "broad focus" refers to sentences that do not have any particular part highlighted, such as the answer to a general question such as "What happened?", and "narrow focus" referring to sentences where a word or phrase is highlighted to draw the listener's attention (e.g., Chafe 1976).

In English and Dutch, narrow focus exhibits a higher f0 peak and longer segments (Pierrehumbert 1980; Cooper et al. 1985; Eefting 1991; Cambier-Langeveld \& Turk 1999; Xu \& Xu 2005). Other cues have also been found to correlate with focus, namely increased duration and intensity, and sometimes effects on segment quality and spectral tilt (Campbell \& Beckman 1997; Niebuhr 2012; Arvaniti 2016). For example, in Finnish, Arnhold and Kyröläinen (2017) note that words in narrow focus have longer duration, wider f0 range, higher intensity peaks and more breathy voice quality. In Guaraní, focus was found to induce longer stressed syllables (Clopper \& Tonhauser 2013). Kelly and Smiljanić (2017) found that in East Norwegian, only phonologically long vowels became longer in narrow focus. This is similar to what has previously been found for Swedish (Bruce 1977; 1981; Bannert 1979), resulting in narrow focus exaggerating the phonemic length contrast.

There has been some work on focus in Arabic: in Najdi Arabic, spoken in Saudi Arabia, contrastive focus was found to increase duration of words and stressed vowels (Almalki 2020); in that study, only phonologically long vowels were examined. Focus in Egyptian Arabic was not found to affect the duration of the syllable (Hellmuth 2011). For Lebanese Arabic, Chahal (2001) examined the Tripoli dialect spoken in the north of Lebanon. This study examined lexically stressed syllables with the (short) vowels [a, i, u] when unaccented, accented and nuclear accented. This was done by having participants read sentences with three target words (initial, medial and final position in the sentence), in response to different questions that elicited either broad focus or narrow focus on one of the three target words. Results showed that f0, intensity, duration and vowel quality differed in each of these conditions, with each of these measures increasing (and vowel quality becoming more peripheral) as prominence level increased (Chahal 2003).

\subsection{Current study}

In the current study, relevant segmental aspects of the Beirut dialect are examined, including phonological vowel length and syllable structure, and how these interact to affect vowel, rime, 
syllable and word duration. The findings regarding vowel and rime duration will have implications for the theory of mora-sharing in Levantine Arabic, based on the concept that phonetic duration reflects moraic structure. The interaction of these measures with prosody is also investigated to determine what effects contrastive focus has on these durations. This experiment expands on previous work in a number of ways: first, by looking at different types of onsets as well as syllable structures. Second, there is no large-scale quantitative research on Lebanese Arabic specifically examining effects on vowel and rime duration in syllables closed by a non-geminate, that is, a singleton consonant that is part of an intervocalic consonant cluster: CV(V)C.CV. The interaction with focus has also not been investigated in the Beirut dialect before.

\section{Method}

\subsection{Participants}

Participants were six (three females, three males) adult native speakers of Lebanese Arabic, aged 18-22. They were students at the American University of Beirut and were paid US\$10 for their time. They were all fluent speakers of English and two were also proficient in French. Recording took about ten minutes.

\subsection{Procedure}

Participants were seated in a DemVox sound booth in the Department of English at AUB. The sentences were presented on paper in a Latinized version of the Arabic alphabet, with an average of 20 sentences per sheet. This is the orthography developed and used by young people for text messages and social media, so it was employed here to ensure vernacular productions. The Arabic orthography is often associated with Classical Arabic or Modern Standard Arabic, and thus more formal situations. Participants were also asked to speak as they would to their friends, and had no difficulty using colloquial Lebanese Arabic for the experiment. They were recorded with a Zoom H5 recorder using the internal microphone.

\subsection{Stimuli}

The target words were all disyllabic. In this experiment, the two focus conditions are referred to as "non-focused" and "contrastive focus" (Chafe 1976; Rooth 1985; Selkirk 2008; Katz \& Selkrik 2011). In the first condition, in order to ensure the target word did not receive focus, two other words in the carrier sentence were contrastively focused with one another. Therefore, the target word is non-focused, rather than the entire sentence receiving broad focus. In the second condition, the target word is contrastively focused with another word in the sentence. There were two sentence types similar to the carrier sentences used in de Jong and Zawaydeh (2002), so that each target word was produced non-focused $(\mathrm{X})$ and in contrastive focus in phrase-medial position (Y): 
Non-focused:

['Pana '?Ilit X mIs huwe]

"I said X not him."
Contrastive focus:

['?ana '?ilit Y mIs Z]

"I said Y not Z."

The sentences were presented in blocks, with all short vowels together and all long vowels together. This is because vowel length is not marked in the orthography used, and we wanted to ensure that participants were confident in the form of the target words they were recording. In terms of syllable structure, this was randomly assigned throughout the blocks, that is, each block contained a mixture of open and closed syllables. The non-focused blocks were presented first, followed by the focused blocks. This was to ensure that participants got used to which words were supposed to be focused, rather than being distracted and having to read each sentence multiple times to get the intended focus.

\section{Target words}

Words were chosen to investigate vowel length (L or S) and syllable structure (for long vowels, open vs closed by a singleton; for short vowels, open vs closed by a singleton vs closed by a geminate). (Long vowels followed by intervocalic geminates were not examined in the current study because these had previoulsy been extensively examined by Khattab and Al-Tamimi (2014)). All measurements were taken on the initial, stressed syllable. The midpoint of the geminate was taken as the end of the stressed syllable, similar to Chahal (2001), and also as analyzed by Al-Tamimi (2004). This is because Arabic does not allow onsetless syllables, so the whole geminate constitutes the coda of the stressed syllable as well as the onset of the following syllable. Stimuli were all disyllabic words with initial stress, and are listed in Table $\mathbf{1 .}$

All words were coded for the above variables, as well as for vowel quality, onset complexity ( $\mathrm{C}$ vs CC) and voicing of the consonants preceding and following the stressed vowel. A number of words were repeated (btije, mnije, btekle, btekhde) to balance the numbers of tokens for short and long vowels, giving a total of 40 tokens non-focused and 40 tokens in contrastive focus (20 short vowels: 8 open syllable, 7 closed by a singleton, 5 closed by a geminate; 20 long vowels: 10 long vowels open syllable, 10 long vowels closed by a singleton). This gave 80 tokens per speaker, so 480 total, with eight removed due to errors in reading or noise due to shuffling papers. The final number of tokens was 472 .

\subsection{Labelling and measurements}

The Praat PlugIn EasyAlign (Goldman 2011) was used for annotation of the sound files. The Spanish version of EasyAlign Goldman and Schwab (2014) turned out to be very accurate for the annotations of Lebanese Arabic. The Spanish one was chosen because the vowels are similar between Spanish and Lebanese Arabic, and Spanish has a /x/, /r/ and /r/ like Arabic. Some 


\begin{tabular}{|l|l|l|l|}
\hline $\mathbf{V}$ & Open & Closed (Singleton) & Closed (Geminate) \\
\hline $\begin{array}{l}\text { bije (I come) } \\
\text { sherib (he drank) } \\
\text { daras (he studied) } \\
\text { btije (you (f) come) } \\
\text { mnije (we come) } \\
\text { b7ammam (I shower) }\end{array}$ & $\begin{array}{l}\text { binzal (I go down) } \\
\text { be7ke (I speak) } \\
\text { birja3 (I come back) } \\
\text { mninzal (we go down) } \\
\text { mnishrab (we drink) } \\
\text { mne7ke (we speak) } \\
\text { mnirja3 (we come back) }\end{array}$ & $\begin{array}{l}\text { ballash (he began) } \\
\text { baddi (I want) } \\
\text { jarrab (he tried) } \\
\text { bjarrib ( I try) } \\
\text { bzekker (I remind) }\end{array}$ \\
\hline VV & $\begin{array}{l}\text { jebit (he is bringing) } \\
\text { 7asis (he is feeling) } \\
\text { semi3 (he is listening) } \\
\text { meshe (let's go) } \\
\text { rayi7 (he is going) } \\
\text { btekol (you (m) eat) } \\
\text { stehal (he deserves) } \\
\text { mnekol (we eat) } \\
\text { mnekhud (we take) } \\
\text { btekhud (you (m) take) }\end{array}$ & $\begin{array}{l}\text { ray7a (she is going) } \\
\text { sekne (she lives) } \\
\text { 2ekle (she is eating) } \\
\text { sherbe (she is drinking) } \\
\text { khalsa (she is finishing) } \\
\text { btekle (you (f) eat) } \\
\text { btekhde (you (f) take) }\end{array}$ & \\
& & \\
\hline
\end{tabular}

Table 1: Target words in the Latinized orthography. $(\mathrm{sh}=/ \mathrm{J} /, \mathrm{j}=/ 3 /, \mathrm{kh}=/ \mathrm{x} /, 7=/ \mathrm{h} /, 3=$ $/ \mathrm{S} /, 2=/ \mathrm{R} / \mathrm{)}$.

regular changes that needed to be made to the textfiles were: inserting $/ \mathrm{h} /$ or $/ \mathrm{h} /$ as $/ \mathrm{x} / \mathrm{h} / \mathrm{S} /$ as $/ \mathrm{a} /$ and $/ \mathrm{J} / \mathrm{as} / \mathrm{s} /$. The annotations were manually adjusted for any errors in the aligning of segments.

Praat scripts by Lennes (2017) were edited and then run to measure target word duration and segment duration.

Calculations included onset duration, rime duration and stressed syllable duration. For syllables closed by a geminate consonant, half of the geminate duration was counted as the coda. Figure 3 shows one annotated sentence, with the target word highlighted. The top tier was the most relevant for the current study, since this annotates each segment.

\subsection{Statistical analysis}

A linear mixed effects regression analysis was conducted using the lmerTest (Kuznetsova, Brockhoff, \& Christensen 2017) package in R (R Development Core Team 2008). The dependent variables were word, vowel, syllable and rime duration. The independent variables that were considered as possible fixed factors were CONDITION (non-focused or contrastive focus), VOWEL LENGTH (L or S), SYLLABLE STRUCTURE (open, closed by a singleton or closed by a geminate) and ONSET COMPLEXITY (C or CC). In a regression model, the reference level is the alphabetically first one, so for example, for VOWEL LENGTH this was the long vowels, and the short vowels 


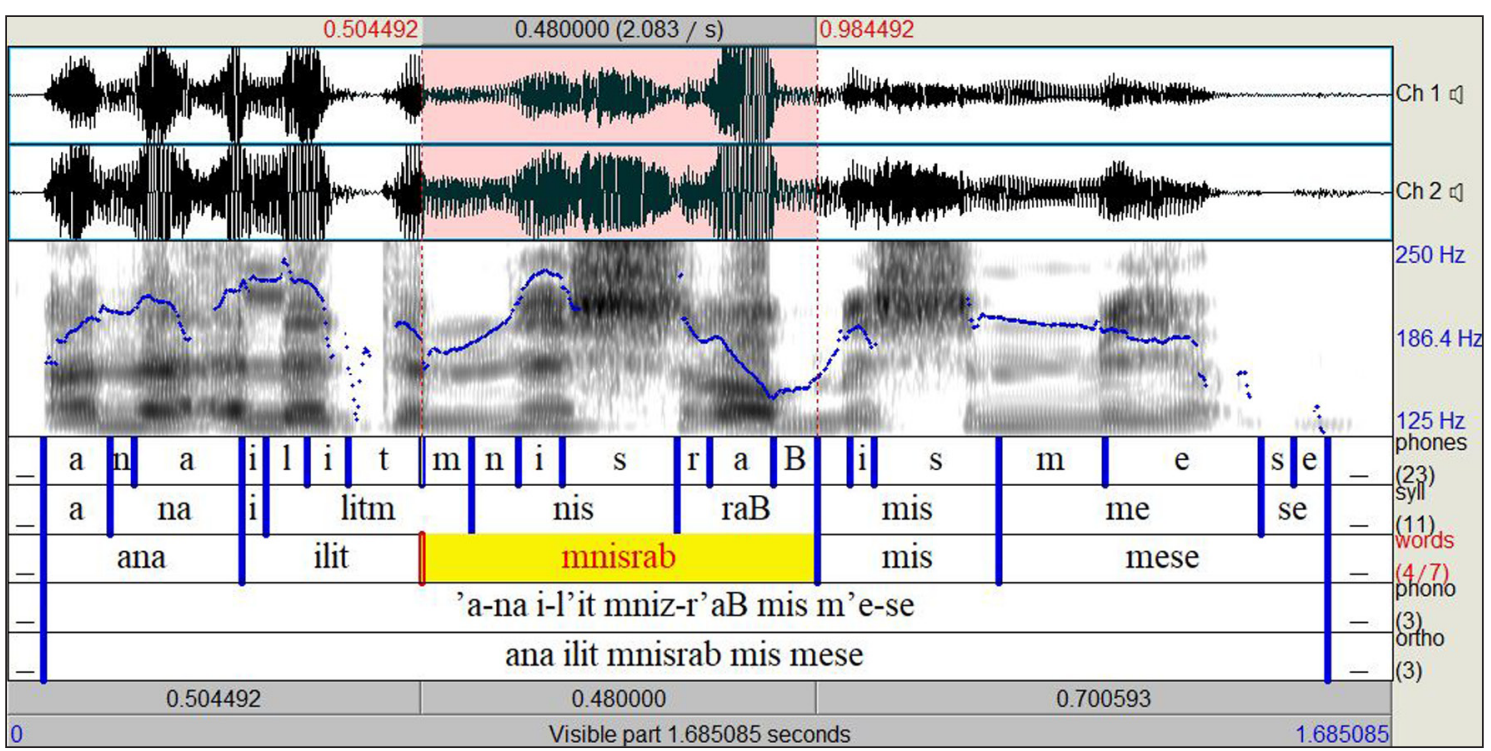

Figure 3: Example sentence showing annotation; target word mnishrab ("we drink").

were compared to the reference level. For CONDITION the reference level was the contrastive focus condition. For each dependent variable, models were built up and compared using the anova function to determine which best explained the data. These will be discussed in turn for each measure. Random intercepts for SPEAKER and either TOKEN or VOWEL QUALITY (i, a, e) (depending on which was a better fit) were included in each model; random slopes tended to result in convergence errors. When there were more than two levels in an independent variable, and there was a significant main effect or interaction, a pairwise test was subsequently run using the emmeans package (Lenth 2019), with a Tukey adjustment for running multiple tests. An alpha-level of 0.01 was chosen to reduce the chances of a false positive result.

\subsection{Hypotheses}

Word, syllable, rime and vowel duration are all predicted to be longer in contrastive focus. It is expected that phonologically long vowels will have significantly longer duration than short vowels. Based on the analysis by Broselow et al. (1997) that codas only have weight in syllables with a long vowel, we expect that coda consonants have no effect on vowel duration when the vowel is short, that is, only phonologically long vowels will shorten in closed syllables. Similarly, we expect rime duration to be in line with predictions of moraicity, whereby $\mathrm{V}$ is monomoraic, and VC, VV and VVC are all bimoraic, based on work by Broselow et al. (1997), Bamakhramah (2009) and Khattab and Al-Tamimi (2014). This predicts rime durations of the following pattern: V $<$ VC, VG, VV, VVC. Syllables with a complex onset are expected to be longer than those with a simple onset, and syllables with a phonologically long vowel are expected to be longer than 
those with a short vowel. Closed syllables are expected to be longer than open syllables. For all measures, syllables closed by a singleton consonant and those closed by a geminate consonant are not expected to differ from one another.

\section{Results}

Multiple linear regression mixed models were built up and compared, with the possible independent variables as listed in Section 2.5. ${ }^{2}$

For word duration, the best model was one with CONDITION and ONSET COMPLEXITY as independent fixed factors, without an interaction, and random intercepts for SPEAKER and TOKEN (R code: lmer(Word.Duration Condition + Onset + (1|Spk) + (1|Token))). This model showed that word duration was longer when the word was in contrastive focus and also when it had a complex onset (CC), (Figure 4). The statistical results for word duration are in Table 2.

For vowel duration, a further possible independent variable of the VOICING of the consonant following the stressed vowel was also explored as a fixed factor, but was not found to improve the models. The best model was one with VOWEL LENGTH, CONDITION and SYLLABLE STRUCTURE as

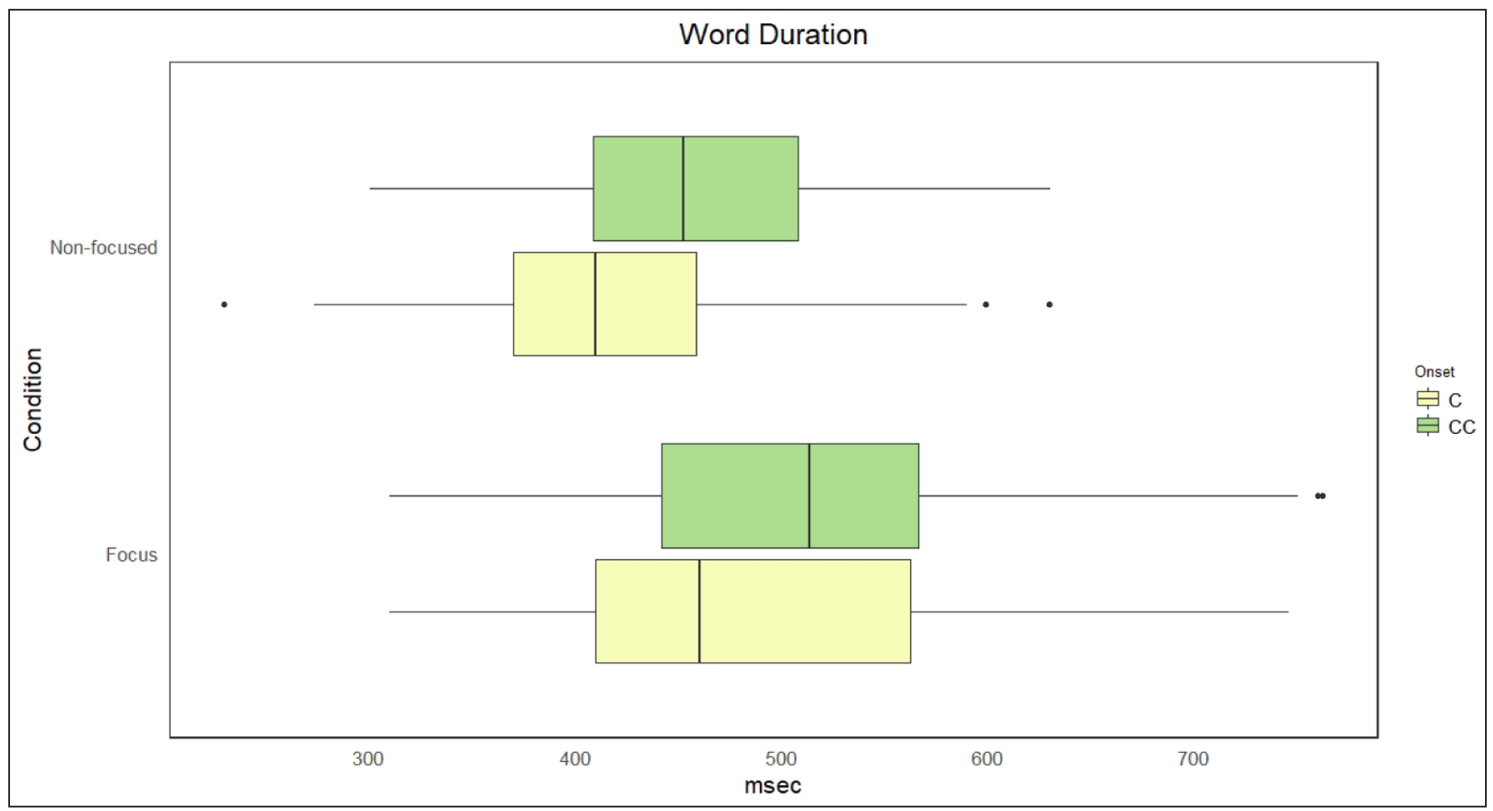

Figure 4: Word duration by onset complexity and condition.

\footnotetext{
${ }^{2}$ The anova model comparison results are in the Appendix, to show that the independent variables that were not included in the best model do not improve that model.
} 
fixed factors, with an interaction, and random intercepts for SPEAKER and VOWEL QUALITY ( $R$

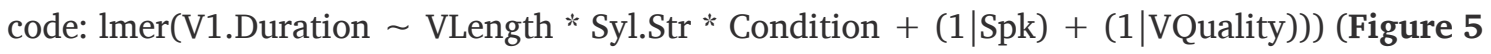
and Table 3).

\begin{tabular}{|l|l|l|l|l|}
\hline Factor & Coef. & SE & $\mathbf{t}$ & $\boldsymbol{p}$ \\
\hline Intercept & 436.05 & 29.96 & 14.55 & $<0.001 *$ \\
\hline Condition.NF & -60.24 & 5.59 & -10.78 & $<0.001 *$ \\
\hline Onset.CC & 44.67 & 514.87 & 3 & $<0.01 *$ \\
\hline
\end{tabular}

Table 2: Statistical results for word duration.

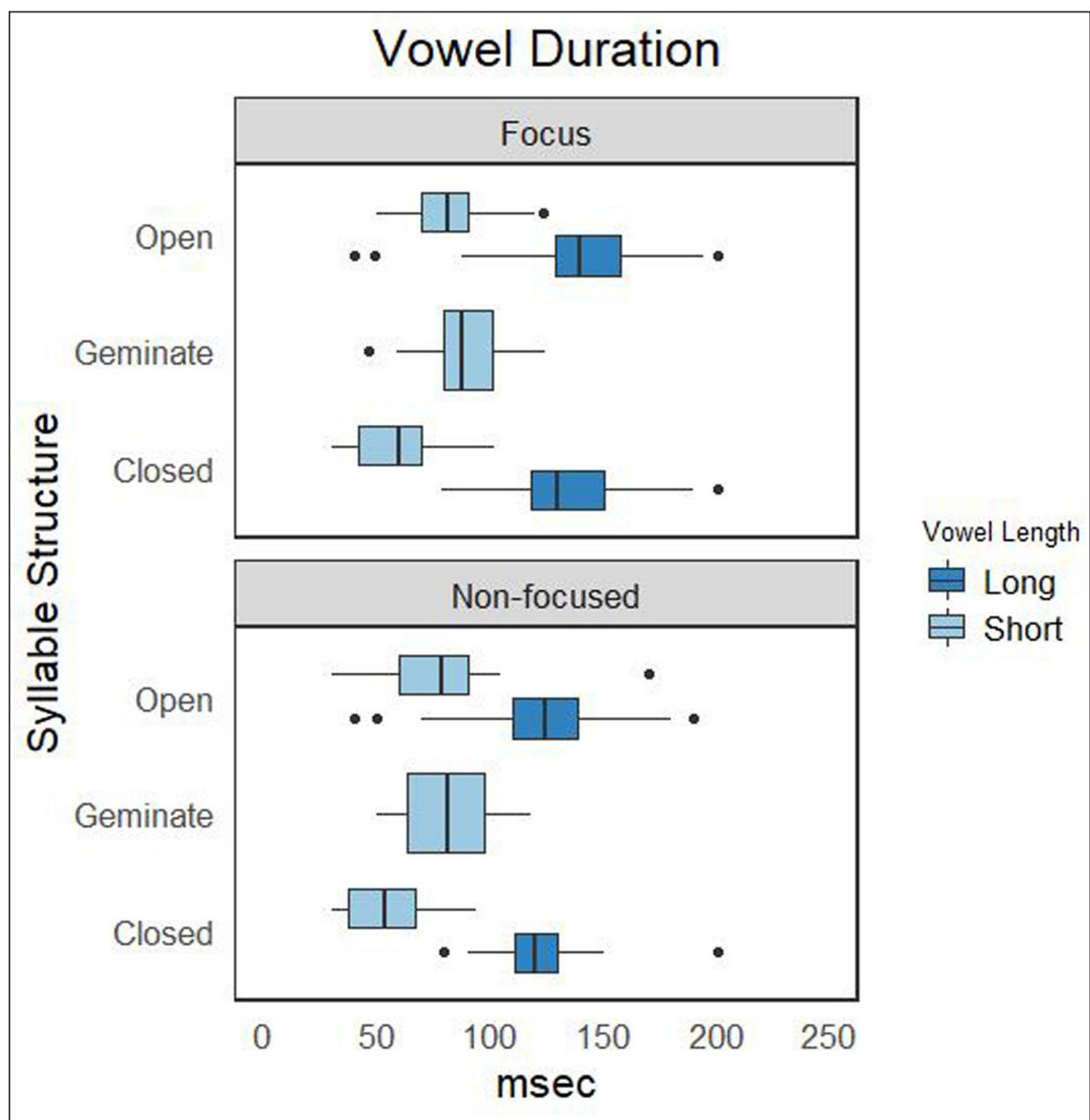

Figure 5: Stressed vowel duration by phonological vowel length, syllable structure and condition. 


\begin{tabular}{|c|c|c|c|c|}
\hline Factor & Coef. & SE & $t$ & $p$ \\
\hline Intercept & 129.15 & 5.5 & 23.5 & $<0.001 *$ \\
\hline VLength.S & -70.19 & 5.01 & -14 & $<0.001 *$ \\
\hline Condition.NF & -13.34 & 4.01 & -3.3 & $<0.001 *$ \\
\hline SylType.Gem & 30.26 & 5.84 & 5.18 & $<0.001 *$ \\
\hline SylType.Open & 4.4 & 3.98 & 1.1 & 0.269 \\
\hline VLength.S: Condition.NF & 10.7 & 6.2 & 1.7 & 0.087 \\
\hline VLength.S: SylType.Open & 21.8 & 6.21 & 3.5 & $<0.001 *$ \\
\hline Condition.NF: SylType.Gem & -4.1 & 7 & -0.59 & 0.559 \\
\hline Condition.NF: SylType.Open & -3.48 & 5.56 & -0.63 & 0.532 \\
\hline VLength.S: Condition.NF: SylType.Open & 2.6 & 8.9 & 0.3 & 0.769 \\
\hline \multicolumn{5}{|l|}{ Pairwise tests } \\
\hline Long, Closed, NF - Short, Closed, NF & 59.5 & 5.27 & 11.3 & $<0.001 *$ \\
\hline Long, Open, NF - Short, Open, NF & 35.1 & 5.5 & 6.4 & $<0.001 *$ \\
\hline Long, Closed, Foc - Short, Closed, Foc & 70.2 & 5.25 & 13.37 & $<0.001 *$ \\
\hline Long, Open, Foc - Short, Open, Foc & 48.39 & 5.1 & 9.5 & $<0.001 *$ \\
\hline Long, Closed, Foc - Long, Closed, NF & 13.34 & 4.01 & 3.32 & 0.045 \\
\hline Long, Open, Foc - Long, Open, NF & 16.8 & 3.9 & 4.36 & $0.001 *$ \\
\hline Short, Closed, Foc - Short, Closed, NF & 2.64 & 4.8 & 0.55 & 1 \\
\hline Short, Open, Foc - Short, Open, NF & 3.5 & 4.97 & 0.71 & 0.999 \\
\hline Short, Gem, Foc - Short, Gem, NF & 6.7 & 5.1 & 1.3 & 0.977 \\
\hline Long, Foc, Closed - Long, Foc, Open & -4.4 & 4 & -1.11 & 0.994 \\
\hline Long, NF, Closed - Long, NF, Open & -0.92 & 3.9 & -0.24 & 1 \\
\hline Short, Foc, Closed - Short, Foc, Open & -26.2 & 4.77 & -5.5 & $<0.001^{*}$ \\
\hline
\end{tabular}

(Contd.) 


\begin{tabular}{|l|l|l|l|l|}
\hline Factor & Coef. & SE & t & $\boldsymbol{p}$ \\
\hline Short, NF, Closed - Short, NF, Open & -25.3 & 5 & -5.06 & $<0.001^{*}$ \\
\hline Short, Foc, Closed - Short, Foc, Gem & -30.26 & 6.2 & -4.9 & $<0.001^{*}$ \\
\hline Short, NF, Closed - Short, NF, Gem & -26.16 & 6.2 & -4.2 & $<0.01^{*}$ \\
\hline Short, Foc, Gem - Short, Foc, Open & 4.1 & 5.9 & 0.69 & 0.999 \\
\hline Short, NF, Gem - Short, NF, Open & 0.84 & 6.3 & 0.13 & 1 \\
\hline
\end{tabular}

Table 3: Statistical results for vowel duration.

The results of the pairwise tests showed that long vowels were significantly longer than short vowels in both open and closed syllables, whether focused or not. For long vowels, there was no difference in duration based on whether the syllable was open or closed. For short vowels, those in syllables closed by a singleton (the first $\mathrm{C}$ in an intervocalic cluster) were significantly shorter than those in open syllables and than those in syllables closed by a geminate consonant. There was no significant difference between short vowels that were followed by a geminate and those in an open syllable, similar to what was found by Khattab and Al-Tamimi (2014). Finally, long vowels in open syllables were significantly longer in contrastive focus, but long vowels in closed syllables were only significantly longer in contrastive focus at an alpha-level of 0.05 , which was not the chosen level for this study, but a larger sample size may lead to significance (see Figure 5). Short vowels were not significantly affected by focus. In the non-focused condition, long vowels are an average of $122 \mathrm{msec}$, and short vowels $71 \mathrm{msec}$. In the focused condition, long vowels are an average of $136 \mathrm{msec}$, and short vowels $76 \mathrm{msec}$.

The speakers did not all read the sentences at the same speech rate (Figure 6), with two speakers having a slower rate than the other four. However, this difference did not appear to affect the duration patterns. Figure 7 shows the vowel duration patterns broken down by speaker. It can be seen that the same general pattern holds.

For rime duration, the best model was one with three fixed factors: SYLLABLE STRUCTURE, CONDITION and VOWEL LENGTH and no interaction, and random intercepts for SPEAKER and VOWEL QUALITY (R code: Imer(Rime.Duration Syl.Str + Condition + Vlength + (1|Spk) $+(1 \mid$ VQuality))). The statistical results for rime duration are in Table 4. Rime duration was significantly longer when the rime contained a phonologically long vowel or when it was in contrastive focus. Since SYLLABLE STRUCTURE has three levels, a pairwise test was necessary to examine these variables. These results showed that open syllables had a significantly shorter rime than syllables closed by a singleton or geminate consonant, and there was no difference between the latter two. Since there is no interaction, the main effects of SyLLABLE STRUCTURE 


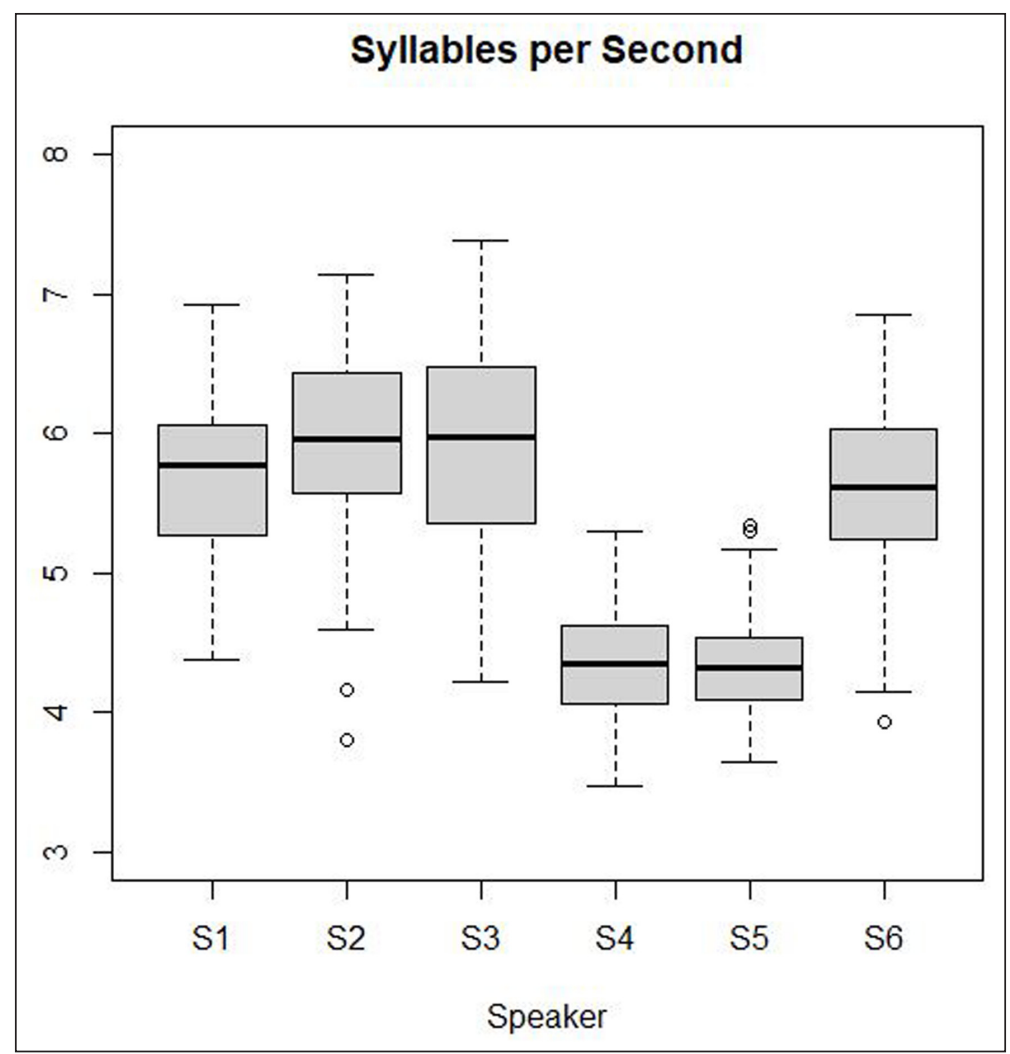

Figure 6: Speech rate, in syllables per second, by speaker.

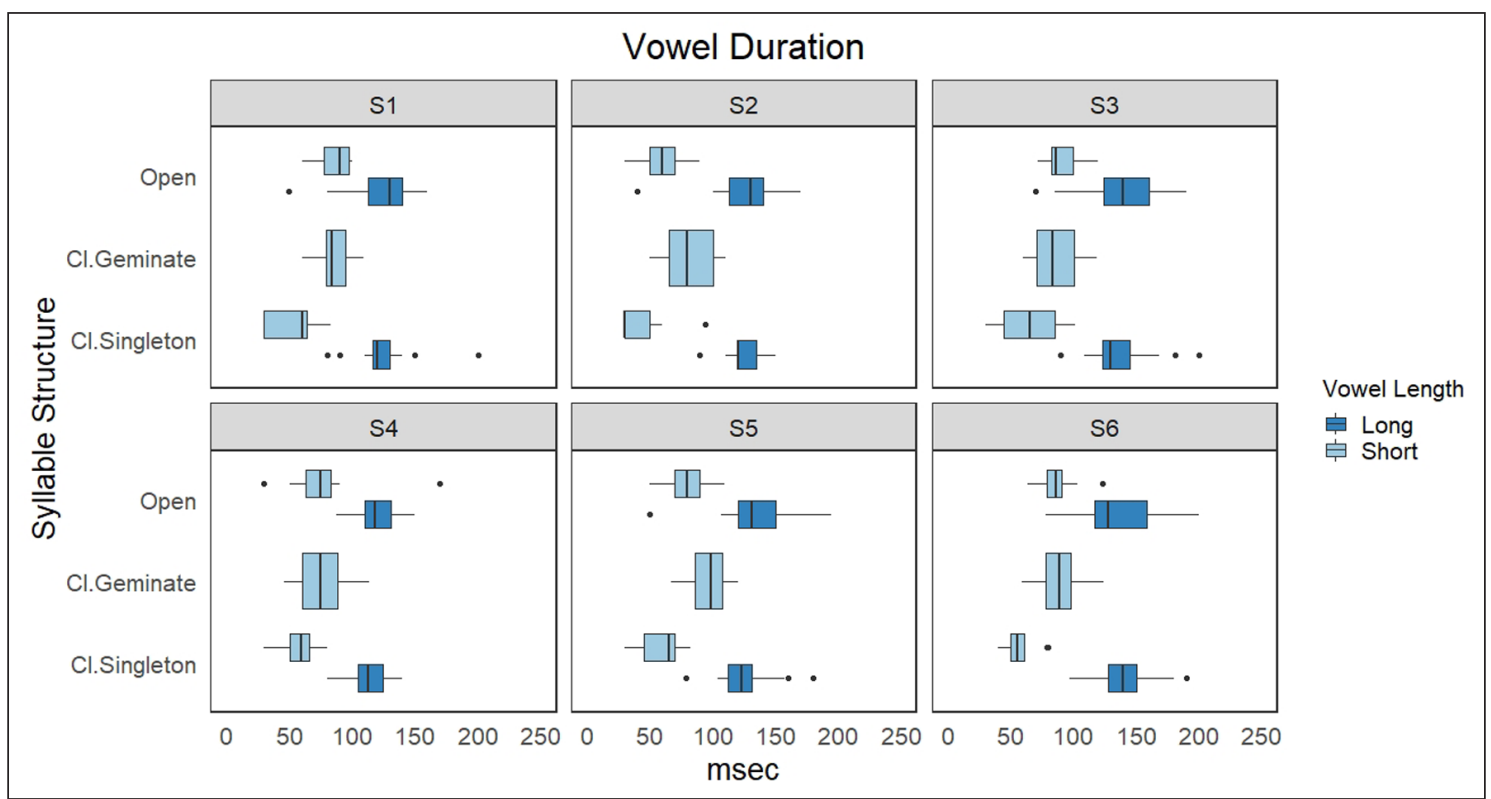

Figure 7: Stressed vowel duration by phonological vowel length and syllable structure, by speaker. 


\begin{tabular}{|l|l|l|l|l|}
\hline Factor & Coef. & SE & $\mathbf{t}$ & $\boldsymbol{p}$ \\
\hline Intercept & 201.66 & 8.96 & 22.5 & $<0.001^{*}$ \\
\hline VLength.S & -37.22 & 4.3 & -8.6 & $<0.001^{*}$ \\
\hline Condition.NF & -16.29 & 2.5 & -6.4 & $<0.001^{*}$ \\
\hline SylType.Gem & 0.27 & 5.8 & 0.04 & 0.963 \\
\hline SylType.Open & -73.04 & 2.75 & -26.57 & $<0.001^{*}$ \\
\hline Pairwise tests & & & & \\
\hline Closed - Gem & -0.27 & 6.08 & -0.04 & 0.999 \\
\hline Closed - Open & 73.04 & 2.75 & 26.57 & $<0.001^{*}$ \\
\hline Gem - Open & 73.31 & 6.03 & 12.2 & $<0.001^{*}$ \\
\hline
\end{tabular}

Table 4: Statistical results for rime duration.

and VOWEL LENGTH indicate that open and closed rimes with a long vowel (VV and VVC) have a difference in duration from one another. (This was also corroborated by a pairwise test where VV and VVC differed at $p<0.001)$. This can be seen in Figure 8.

For syllable duration, the best model was the one with four fixed factors: SyLLABLE STRUCTURE, CONDITION, VOWEL LENGTH and ONSET COMPLEXITY, with no interactions, and random intercepts for SPEAKER and TOKEN (R code: lmer(Syl.Duration Syl.Str + Condition + Vlength + Onset $+(1 \mid$ Spk $)+(1 \mid$ Token $)))$. The statistical results for syllable duration are in Table 5. All four independent variables had a highly significant effect on syllable duration, with the Coefficients showing that syllables were longer when in contrastive focus, when they contained a long vowel, or when they had a complex onset (Figure 9). The pairwise tests for SYLLABLE STRUCTURE showed that - similar to the results for rime duration - open syllables were significantly shorter than syllables closed by a singleton and than those closed by a geminate coda, while the latter two did not differ from one another.

To summarize the results, target words were significantly longer when in contrastive focus and when they had a complex onset. Syllables were also significantly longer when in contrastive focus and when they had a complex onset, but also when they contained a phonologically long vowel and when they were closed. Vowel duration was significantly affected by phonological vowel length. Long vowels had no duration difference regardless of whether they were in an open or closed syllable, while short vowels were significantly shorter in singleton-closed syllables than open syllables or when closed by a geminate. Long vowels were longer under contrastive focus 


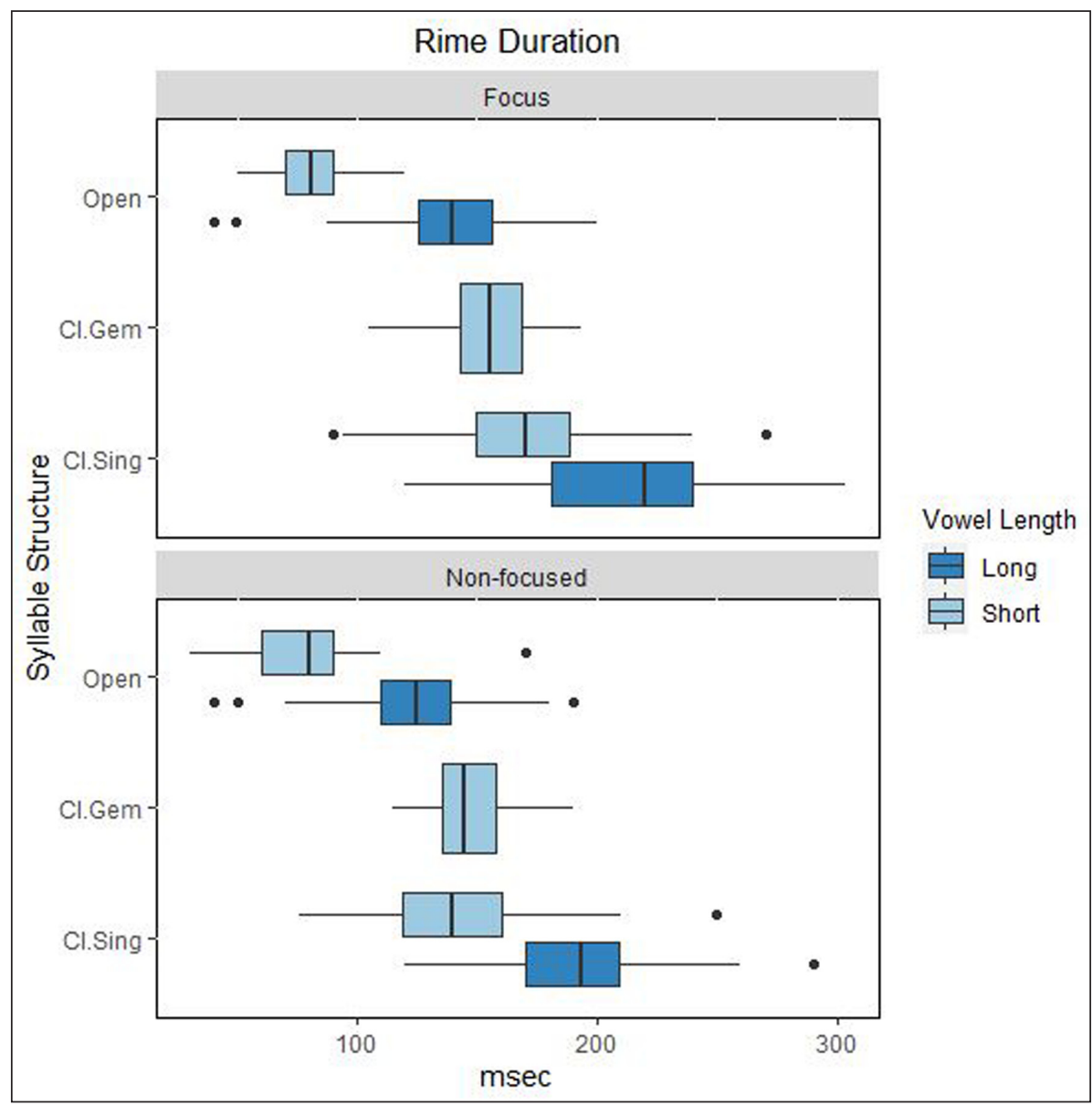

Figure 8: Rime duration by phonological vowel length, syllable structure and condition.

when in an open syllable (with those in a closed syllable approaching significance), but short vowels were not. Rime duration was significantly longer when rimes contained a long vowel or when they were closed, and were in contrastive focus. Figure 10 shows average durations for segments in different syllable types in the non-focused condition. The shorter vowel in VC syllables can be seen, and it is also notable that the coda consonant in VC vs VG is shorter when part of a geminate than a signleton consonant (this is further dicussed in section 4.2).

\section{Discussion}

\subsection{Effects of focus}

Contrastive focus was associated with an increase in duration of the target word, stressed syllable and rime. Long vowels in open syllables were longer in contrastive focus, and long vowels in closed syllables were approaching significance in this condition. The findings for syllable duration differed from findings on Egyptian Arabic, where focus was not found to affect stressed syllable 


\begin{tabular}{|l|l|l|l|l|}
\hline Factor & Coef. & SE & $\mathbf{t}$ & $\boldsymbol{p}$ \\
\hline Intercept & 237.87 & 15.88 & 14.9 & $<0.001^{*}$ \\
\hline SylType.Gem & 6.26 & 12.97 & 0.48 & 0.632 \\
\hline SylType.Open & -69.18 & 9.22 & -7.5 & $<0.001^{*}$ \\
\hline Condition.NF & -27.7 & 3.4 & -8.14 & $<0.001^{*}$ \\
\hline VLength.S & -55.3 & 8.7 & -6.35 & $<0.001^{*}$ \\
\hline Onset.CC & 63.9 & 8.45 & 7.56 & $<0.001^{*}$ \\
\hline Pairwise tests & & & & \\
\hline Closed - Gem & -6.26 & 12.97 & -0.48 & 0.879 \\
\hline Closed - Open & 69.18 & 9.22 & 7.5 & $<0.001^{*}$ \\
\hline Gem - Open & 75.45 & 13.5 & 5.6 & $<0.001^{*}$ \\
\hline
\end{tabular}

Table 5: Statistical results for syllable duration.

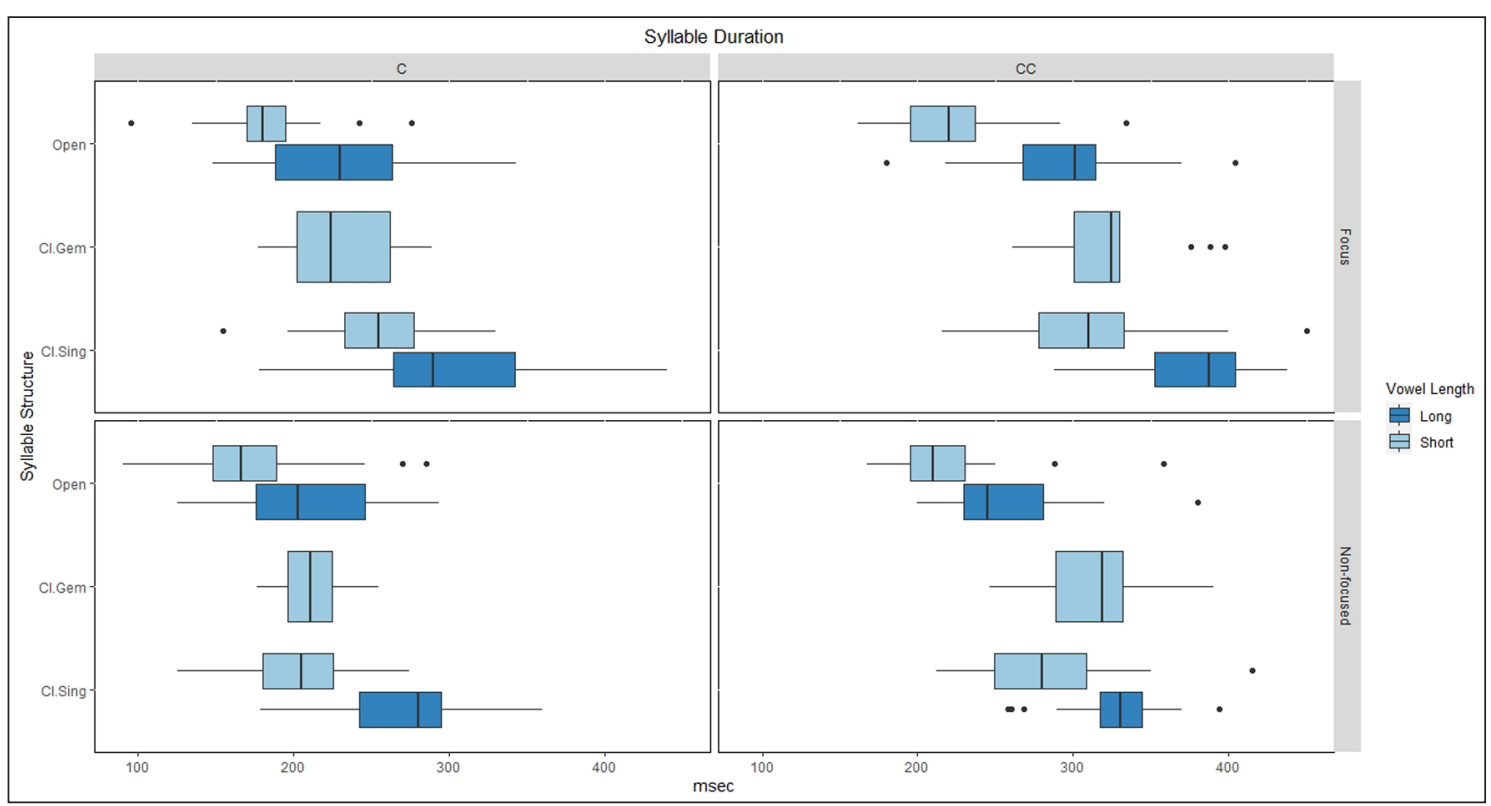

Figure 9: Stressed syllable duration by condition, vowel length, onset and syllable structure.

duration (Hellmuth 2011); however, that study did not directly compare the same target words when non-focused and in contrastive focus, so the different methodology means that study and the current one are not directly comparable. The vowel results also differ from those found in 


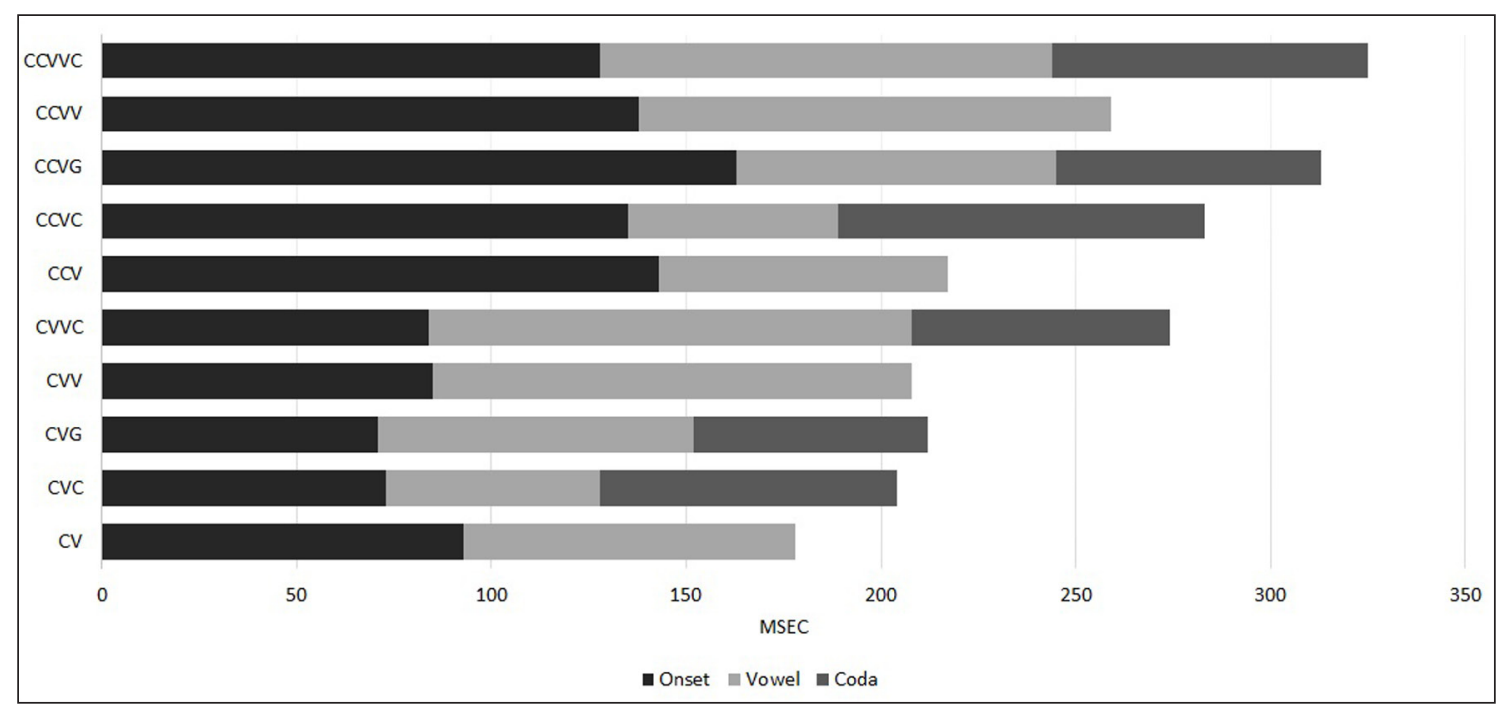

Figure 10: Average segment durations (non-focused) for stressed syllables by syllable structure.

the Tripoli dialect, where short vowels were longer in contrastive focus (Chahal 2003). However, the results found here are similar to those found in an examination of phrase-final lengthening in the Beirut dialect, where only phonologically long vowels were lengthened in this position (Kelly 2021).

\subsection{Segments and syllables}

Word duration was found to be longer when the target word was contrastively focused, as noted above, as well as when it had a complex onset, but not when the stressed syllable contained a long vowel.

Syllables were found to be longer when they were closed and when they had a complex onset or a long vowel, and also when contrastively focused, all in line with the hypotheses.

Vowel duration was always significantly longer for phonologically long vowels, as predicted. When non-focused, long vowels were on average $122 \mathrm{msec}$ and short vowels $71 \mathrm{msec}$, which is a ratio of 1:1.72. Hall (2017) summarizes work on other varieties of Arabic finding ratios of 1:1.7 for Syrian, and Broselow et al. (1997) mention ratios of 1:1.51 up to 1:2 for Syrian, Lebanese and Jordanian, and Khattab and Al-Tamimi (2014) found ratios of 1:1.91 to 1:2.1 for Lebanese Arabic, so the current results are in line with all of these. The hypothesis that long vowels would be shorter in closed syllables was not borne out, and in fact was found only for short vowels, which is the opposite of our hypothesis. Short vowels were significantly shorter when they occurred in syllables closed by a singleton than when they were in an open syllable or a syllable with a geminate coda. In their analysis of the Beirut dialect, Khattab and Al-Tamimi (2014) found a similar result for short vowels, because they only examined open syllables or 
syllables closed by a geminate consonant (V vs VG). The results here found no difference in short vowel duration between these two groups either, but we did find that in syllables closed by a singleton consonant (VC), short vowels were shorter. This result does indeed suggest closedsyllable shortening, but it is surprising that it is only found for phonologically short vowels. Although this was not examined statistically in the current study, these shortened vowels also appeared to be different in quality, where they were reduced and centralized when shortened.

When examining syllables and rimes, the geminate was considered to be ambisyllabic, as in previous work (Khattab \& Al-Tamimi 2014) so the full geminate duration was divided in half to represent the coda. The finding that VG and VC do not differ in total rime duration, but V is shorter when in VC than VG, implies that a coda singleton (C) is longer than a coda geminate (G). It is worth noting that in Figure 10, C does in fact appear to be longer than G. This may indicate that a coda singleton weighs more than the first half of an ambisyllabic geminate consonant, thus affecting vowel duration in a compensatory way. Vowels being shorter before singleton consonants than geminate consonants has also been found for Persian (Hansen 2003) and Japanese (Idemaru \& Guion 2008).

The duration of long vowels was not affected by whether they were in an open or closed syllable, which goes against previous findings. When Broselow et al. (1995) and Broselow et al. (1997) examined vowel and coda duration, they examined one speaker each of Jordanian, Syrian and Lebanese Arabic, using one lexeme (kitaab, 'book'), and analyzed the speakers separately, each producing 36 tokens involving long vowels (12 sentences, three repetitions). While all three speakers were found to have a significant difference in vowel duration in VV vs VVC, the method of examining speakers separately, and only using one lexeme, is more likely to lead to effects of idiosyncracies of the speaker and the target word, and a result that is not generalizable. In the current experiment, including speaker and token as random intercepts in the regression model allows for pooling of speakers and target words, increasing the statistical power. The lack of significant improvement of the model when VoICING was added is in line with work on Jordanian Arabic, which found no difference in vowel duration based on voicing of the coda consonant (Mitleb 1984).

The results for rime duration were expected insofar as rimes with a long vowel were longer than those with a short vowel, and that V is shorter than the others, and that VC, VG and VV have similar durations to one another (Figure 8). These results are in line with $\mathrm{V}$ being monomoraic and VC, VG and VV being bimoraic. However, the results for open versus closed rimes containing long vowels were unexpected. We predicted that VVC duration should be in line with VV, due to previous work describing trimoraic syllables as surfacing as bimoraic due to mora-sharing. Assuming that duration is linked to moras (Port et al. 1987; Hayes 1989; Hubbard 1993; Ham 1998; Cohn 2003), VV and VVC should not differ in duration, but VVC was indeed found to be significantly longer than VV, resulting in the following hierarchy: V $<$ VC, VG, VV $<$ VVC. These 
results, while unexpected based on previous work, tie in with the results we found for vowel duration, where there was no evidence of shortening in long vowels, and are indicative of VVC being trimoraic.

However, there is another possible interpretation, that is, that what we call VVC is not in fact closed. The words of (C)CVVCCV(C) structure could have an open initial syllable if they have a vowel inserted between the intervocalic C's, so that the word is in fact trisyllabic: (C)CVV. CV.CV(C). These target words were examined in detail and no acoustic or auditory evidence for epenthesis was found. It should also be noted that all of the target words had similar results for vowel duration, so it is not the case that some of them behaved differently. Another possible reanalysis is that the second syllable is parsed as having a complex onset. For example, a word like btekle, instead of ['bte:k.le] would be ['bte:.kle]. A complex onset would be a way to avoid trimoraic syllables, instead of shortening the vowel. Stress assignment does not clarify the choice of analysis based on the target words currently examined: whether the initial syllable is trimoraic or bimoraic, it will attract stress because it is the initial syllable in a disyllabic word that does not have a superheavy final syllable. Even if the first syllable is bimoraic and the second has a complex onset, onsets do not affect stress assignment in Arabic.

The analysis involving a complex onset in the second syllable has been used by Bamakhramah (2009) for Hadhrami Arabic, where superheavy syllables are avoided by allowing word-internal complex onsets. One issue with this analysis is that some clusters (including some of those used in the current study) would mean that the sonority sequencing principle (SSP) (Selkirk 1984; Clements 1990) would be violated in an onset, for example an onset of [ls] or [rb]. However, there are cases of languages that violate the SSP in onsets, such as the sonority reversals in English spear and sky (Carlisle 2001). Lebanese Arabic allows SSP violations in word-initial clusters, such as nhar (day), or rkeb (knees). In his analysis of Hadhrami Arabic, Bamakhramah (2009) gives examples with onsets of [lb], [rk], for example barrikina syllabified as [ba:.rki..nə] 'bless us' (fem.) (p. 152). He notes that this variety of Arabic "allows onsets to be composed of any biconsonantal cluster" (p221). Likewise in San'ani Arabic, spoken in Yemen, Watson (2002) gives examples of onset clusters that violate the SSP, such as [nx] and [ms] (p. 74). This would be worth examining in a follow-up study, perhaps involving a language game (Botne \& Davis 2000), to investigate how speakers break up syllables. The structure of the trimoraic analysis and the complex onset analysis are shown in Figure 11.

The complex onset analysis would propose that in order to avoid a trimoraic syllable, those with a long vowel and following singleton coda (that would otherwise form a closed syllable) instead have the coda syllabified as the beginning of a complex onset of the following syllable. This does not happen for geminates because geminates are ambisyllabic, so they have to be partly associated with the preceding syllable, and therefore affect vowel duration, as found by Khattab \& Al-Tamimi (2014). This analysis also fits in better than the trimoraic analysis of VVC, 


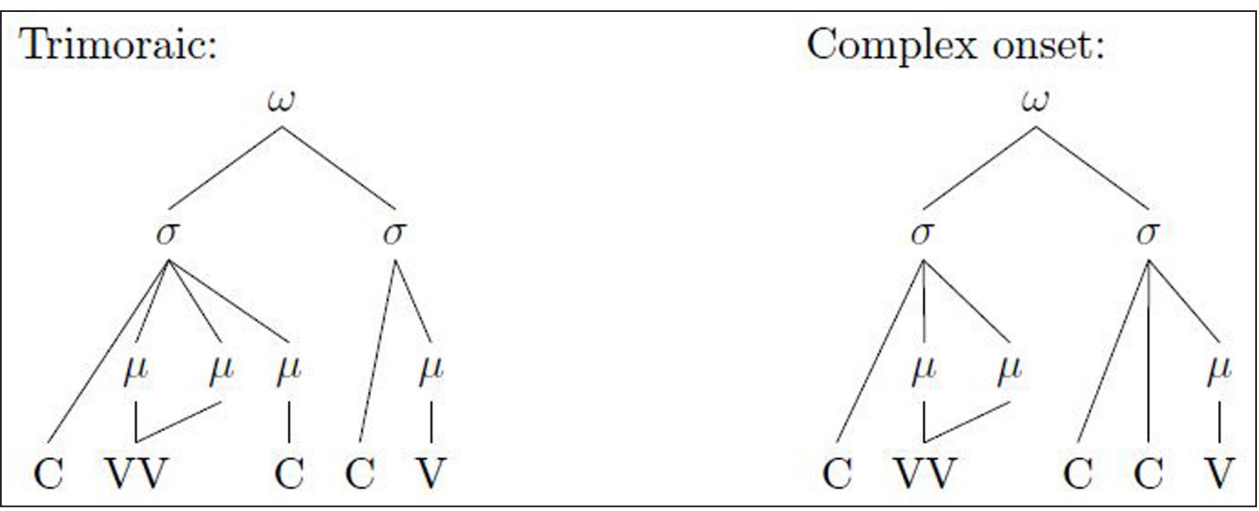

Figure 11: Mora-based representation showing the trimoraic analysis and the complex onset analysis.

because if trimoraic syllables are allowed, a geminate coda would have no need to shorten a long vowel. As such, the complex onset analysis is more straightforward than the trimoraic analysis.

There is one other possible analysis that avoids both trimoraic syllables and word-internal complex onsets, and that is Kiparsky (2003)'s analysis using the concept of semisyllables. As noted in section 1.1.1, a long vowel in a non-final closed syllable would not be shortened because the final $\mathrm{C}$ is a semisyllable, and therefore weighs a mora itself. In response to this, Watson (2007) noted that VC-dialects allow mora sharing "iff the syllable contains a long vowel" (p.354). Based on the results of the current study, we propose adding a further requirement at least for Lebanese Arabic, whereby mora-sharing is permitted iff the syllable contains a long vowel and a following geminate. This implies a different analysis for syllables that have a rime VVC vs VVG. VVG appear to follow the mora-sharing analysis, while VVC follow the semisyllable analysis. Treating consonant clusters differently from geminates is not novel; Watson (2007) also notes that in some Arabic dialects, geminates behave differently from non-geminate clusters, precisely because "geminates...can be reduced by degrees, still maintaining a distinction with simplex consonants" (p.351). The structure of the semisyllable analysis and the mora-sharing analysis are shown in Figure 12.

This semisyllable analysis also avoids the drawback of the complex onset analysis, which involves the typologically unusual pattern of word-internal complex onsets, including some that violate the SSP. Since the semisyllable is separate from the following syllable, the SSP violation does not occur. Previous research on Lebanese Arabic has described sonorant consonants as being syllabic when in an initial or final cluster that would otherwise violate the SSP, such as the /l/ in [1..bu:.me] 'the owl' (Khattab 2002: 98) and the /n/ in [?ib.n,] 'son' (Obegi 1971: 16). This approach fits in with the current analysis, the difference being that in the current study, it is word-internal rather than word-initial or word-final. 


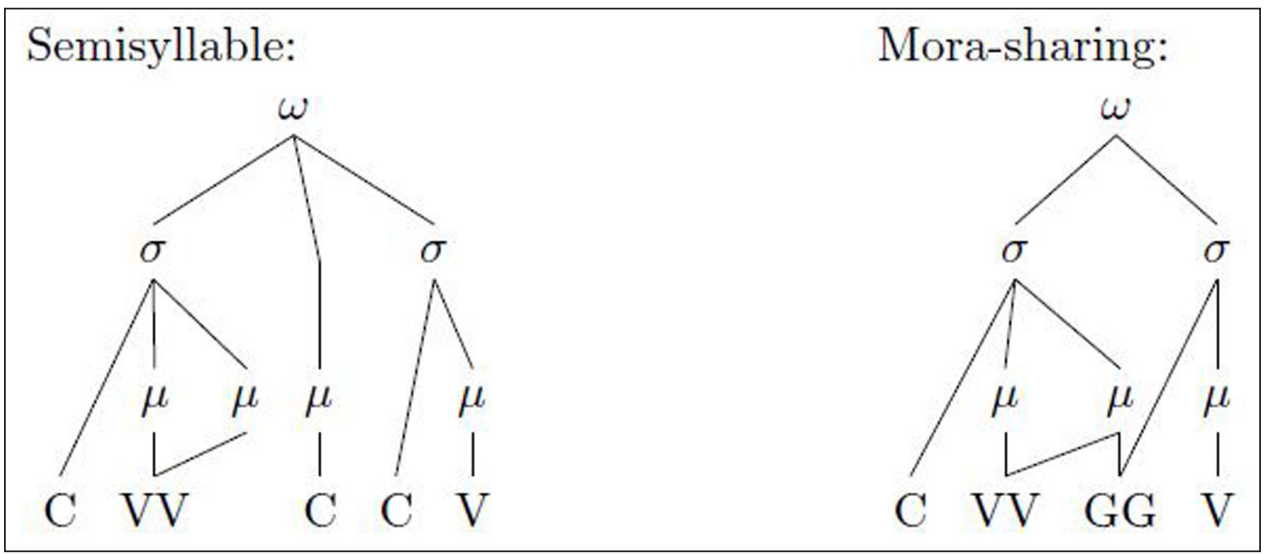

Figure 12: Mora-based representation showing the semisyllable analysis (Kiparsky 2003) and the mora-sharing analysis.

\begin{tabular}{|lllll|}
\hline Rime & Syllable & Example & Result & Analysis \\
\hline Short V & & & & \\
V & Open & CV.CV & & monomoraic \\
VG & Cl. by Geminate & CVG.GV & V not shortened & bimoraic \\
VC & Cl. by Singleton & CVC.CV & V shortened; C >G & bimoraic; compens. shortening \\
\hline Long V & & & & \\
VV & Open & CVV.CV & & bimoraic \\
VVG & Cl. by Geminate & CVVG.GV & V shortened (K. \& Al-T., 2014) & mora-sharing \\
VVC & Cl. by Singleton & CVVC.CV & V not shortened & CVV.C.CV - semisyllable \\
\hline
\end{tabular}

Figure 13: Summary of results and analyses.

Returning to short vowels in the context of this analysis, there is no need for a semisyllable to be formed in VC because the syllable would still not be superheavy. Likewise, there is no need for a geminate coda to affect short vowel duration, for the same reason. The semisyllable and mora-sharing approaches are only used to avoid trimoraic syllables, so neither one occurs with short vowels. A summary of the analysis is provided in Figure 13.

What unites the current findings for long and short vowels and their interaction with syllable structure is that syllables closed with a geminate versus singleton coda behave differently. Short vowels get shorter when followed by a singleton coda but not by a geminate coda. The singleton coda takes up more of the rime than a geminate coda does, as reflected in the durational differences found. Long vowels get shorter before a geminate coda (according to Khattab and Al-Tamimi (2014), but not examined here) but not before a singleton coda. These results suggest a phonetic compensatory shortening for short vowels followed by a singleton coda, but a resyllabification involving a semisyllable in the case of long vowels followed by a non-geminate consonant cluster. 
These findings are based on a quantitative analysis of VG, VC and VVC and indicate that previous assumptions about mora-sharing in Lebanese Arabic may not hold for all contexts. They also suggest that intervocalic geminates and intervocalic non-geminate consonant clusters - in any language - should not be assumed to be phonologically equivalent, or to have the same interaction with the preceding vowel. A hybrid analysis that proposes a different pattern for different types of intervocalic consonants is not entirely economical, but this is what the data for Lebanese Arabic suggest. These results indicate that avoiding superheavy syllables is paramount, even if it requires treating geminates and clusters differently. It would be useful to examine measures of duration in other languages with phonologically long vowels and consonants, for example, Norwegian or Estonian, to examine whether geminate consonants and consonant clusters behave similarly. Future quantitative research on other varieties of Levantine Arabic, for example Jordanian and Syrian, would be helpful to determine whether the same patterns are found for vowels preceding intervocalic non-geminate clusters. 


\section{Appendix}

\section{Word duration}

Best model:

wdur.cnd.ons $=\operatorname{lmer}($ Word.Dur $\sim$ Condition + Onset $+(1 \mid$ Spk $)+(1 \mid$ Token $))$

wdur.cnd.ons.vl $=$ lmer(Word.Dur $\sim$ Condition + Onset + VLength $+(1 \mid$ Spk $)+(1 \mid$ Token $))$

wdur.cnd.ons.vq $=$ lmer(Word.Dur $\sim$ Condition + Onset + VQuality $+(1 \mid$ Spk $)+(1 \mid$ Token $))$

wdur.cnd.ons.syl $=1$ mer(Word.Dur $\sim$ Condition + Onset + Syl.Str $+(1 \mid$ Spk $)+(1 \mid$ Token $))$

\begin{tabular}{|l|l|}
\hline Comparison & $p$ \\
\hline anova(wdur.cnd.ons, wdur.cnd.ons.vl) & 0.148 \\
\hline anova(wdur.cnd.ons, wdur.cnd.ons.vq) & 0.059 \\
\hline anova(wdur.cnd.ons, wdur.cnd.ons.syl) & 0.227 \\
\hline
\end{tabular}

Table A1: Model comparison results for word duration.

\section{Vowel duration}

Best model:

vdur.vl.str.cnd $=$ lmer(V1.Dur $\sim$ VLength * Syl.Str * Condition $+(1 \mid$ Spk $)+(1 \mid$ VQ $))$

vdur.vl.str.cnd.ons $=$ lmer (V1.Dur $\sim$ VLength * Syl.Str $*$ Condition $*$ Onset $+(1 \mid$ Spk $)+$ $(1 \mid \mathrm{VQ}))$

vdur.vl.str.cnd.vc $=$ lmer (V1.Dur $\sim$ VLength * Syl.Str * Condition * Voicing $+(1 \mid$ Spk $)+$ $(1 \mid \mathrm{VQ}))$

\begin{tabular}{|l|l|}
\hline Comparison & $p$ \\
\hline anova(voweld.syl.vl.cnd, voweld.syl.vl.cnd.ons) & 0.441 \\
\hline anova(voweld.syl.vl.cnd, voweld.syl.vl.cnd.vc) & 0.126 \\
\hline
\end{tabular}

Table A2: Model comparison results for vowel duration. 


\section{Rime duration}

Best model:

rimed.syl.vl.cnd $=\operatorname{lmer}($ Rime.Dur $\sim$ Syl.Str + Vlength + Condition $+(1 \mid$ Spk $)+(1 \mid$ VQ $))$

rimed.syl.vl.cnd.ons $=$ lmer(Rime.Dur $\sim$ Syl.Str + Vlength + Condition + Onset $+(1 \mid$ Spk $)$ $+(1 \mid \mathrm{VQ}))$

\begin{tabular}{|l|l|}
\hline Comparison & $p$ \\
\hline anova(rimed.syl.vl.cnd, rimed.syl.vl.cnd.ons) & 0.506 \\
\hline
\end{tabular}

Table A3: Model comparison results for rime duration.

\section{Syllable duration}

Best model:

syld.str.cnd.vl.ons $=\operatorname{lmer}($ Syl.Dur $\sim$ Syl.Str + Condition + Vlength + Onset $+(1 \mid$ Spk $)+$ (1|Token))

syld.str.cnd.vl.ons.vq $=$ lmer(Syl.Dur $\sim$ Syl.Str + Condition + Vlength + Onset + VQuality $+(1 \mid$ Spk $)+(1 \mid$ Token $))$

\begin{tabular}{|l|l|}
\hline Comparison & $\boldsymbol{p}$ \\
\hline anova(syld.str.cnd.vl.ons, syld.str.cnd.vl.ons.vq) & 0.493 \\
\hline
\end{tabular}

Table A4: Model comparison results for syllable duration.

\section{Acknowledgements}

The research used for this investigation was conducted with the support of the American University of Beirut's University Research Board, Award No. 103367. Special thanks to Diane Ghanem for ensuring the orthography was accurate, and to Rasha Noureddine and Christy Choueiri for assistance in coming up with target words and carrier sentences. Thank you to the reviewers and associate editor for helpful comments.

\section{Competing Interests}

The author has no competing interests to declare. 


\section{References}

Abdul-Karim, Kamal. 1980. Aspects of the Phonology of Lebanese Arabic. Doctoral Dissertation, University of Illinois at Urbana-Champaign.

Abu-Salim, Issam \& Abdel-Jawad, Hassan. 1988. Syllable patterns in Levantine Arabic. Studies in the Linguistic Sciences 18(2). 1-22.

Al-Tamimi, Feda Y. 2004. An experimental phonetic study of intervocalic singleton and geminate sonorants in Jordanian Arabic. Al-Arabiyya 37. 37-52.

Almalki, Hussain. 2020. The Production and Perception of Prosodic Prominence in Urban Najdi Arabic. Doctoral Dissertation, George Mason University, Virginia.

Aoun, Yosef. 1979. Is the syllable or the supersyllable a constituent? MIT Working Papers in Linguistic 1. 140-148.

Arnhold, Anja \& Kyröläinen, Aki-Juhani. 2017. Modelling the Interplay of Multiple Cues in Prosodic Focus Marking. Laboratory Phonology 8(1). 1-25. DOI: https://doi.org/10.5334/ labphon.78

Arvaniti, Amalia. 2016. Analytical Decisions in Intonation Research and the Role of Representations: Lessons from Romani. Laboratory Phonology 7(1). 1-43. DOI: https://doi. org/10.5334/labphon.14

Bamakhramah, Majdi A. 2009. Syllable Structure in Arabic Varieties with a Focus on Superheavy Syllables. Doctoral Dissertation, Indiana University, Indiana, United States.

Bannert, Robert. 1979. The effect of sentence accent on quantity. In Proceedings of the 9th International Congress of Phonetic Sciences, 253-259. Copenhagen.

Blevins, Juliette. 1993. A Tonal Analysis of Lithuanian Nominal Accent. Language 69. 237-273. DOI: https://doi.org/10.2307/416534

Botne, Robert \& Davis, Stuart. 2000. Language games, segment imposition, and the syllable. Studies in Language 24(2). 319-344. DOI: https://doi.org/10.1075/sl.24.2.04bot

Broselow, Ellen. 1992. Parametric variation in Arabic dialect phonology. In Broselow, Ellen \& Eid, Mushira \& McCarthy, John J. (eds.), Perspectives on Arabic Linguistics IV, 7-45. Amsterdam and Philadelphia: Benjamins. DOI: https://doi.org/10.1075/cilt.85.04bro

Broselow, Ellen \& Chen, Su-I \& Huffman, Marie. 1997. Syllable weight: convergence of phonology and phonetics. Phonology 14(1). 47-82. DOI: https://doi.org/10.1017/S095267579700331X

Broselow, Ellen \& Huffman, Marie \& Chen, Sui-I \& Hsieh, Ruohmei. 1995. The timing structure of CVVC syllables. In Eid, Mushira (ed.), Perspectives on Arabic Linguistics VII, 119-138. Amsterdam and Philadelphia: Benjamins. DOI: https://doi.org/10.1075/cilt.130.11bro

Bruce, Gösta. 1977. Swedish word accents in sentence perspective. Travaux de L'Institut de Linguistique de Lund 12.

Bruce, Gösta. 1981. Tonal and temporal interplay. In Working Papers 21, 49-60. Dept. of Linguistics, Lund University.

Cambier-Langeveld, Tina \& Turk, Alice E. 1999. A cross-linguistic study of accentual lengthening: Dutch vs. English. Journal of Phonetics 27. 255-280. DOI: https://doi.org/10.1006/jpho.1999.0096 
Campbell, Nick \& Beckman, Mary E. 1997. Accent, stress and spectral tilt. Journal of the Acoustical Society of America 101(5). 3195. DOI: https://doi.org/10.1121/1.419208

Carlisle, Robert. 2001. Syllable structure universals and second language acquisition. International Journal of English Studies 1. 1-19.

Chafe, Wallace L. 1976. Givenness, contrastiveness, definiteness, subjects, topics and point of view. In Li, Charles N. (ed.), Subject and Topic, 27-55. New York: Academic Press.

Chahal, Dana. 2001. Modelling the Intonation of Lebanese Arabic Using the AutosegmentalMetrical Framework: A comparison with English. Doctoral Dissertation, University of Melbourne, Melbourne.

Chahal, Dana. 2003. Phonetic Cues to Prominence in Lebanese Arabic. In 15th International Congress of Phonetic Sciences. Barcelona.

Clements, George N. 1990. The role of the sonority cycle in core syllabification. In Kingston, John \& Beckman, Mary E. (eds.), Papers in Laboratory Phonology I: Between the Grammar and Physics of Speech, 283-333. Cambridge: Cambridge University Press. DOI: https://doi.org/10.1017/ СBO9780511627736.017

Clopper, Cynthia \& Tonhauser, Judith. 2013. The prosody of focus in Paraguayan Guaraní. International Journal of American Linguistics 79(2). 219-251. DOI: https://doi.org/10.1086/669629

Cohn, Abigail. 2003. Phonological structure and phonetic duration: the role of the mora. Working Papers of the Cornell Phonetics Laboratory 15. 69-100.

Cooper, William E. \& Eady, Stephen J. \& Mueller, Pamela R. 1985. Acoustical aspects of contrastive stress in question-answer contexts. Journal of the Acoustical Society of America 77(6). 2142-2156. DOI: https://doi.org/10.1121/1.392372

Davis, Stuart \& Ragheb, Marwa. 2014. Geminate representation in Arabic. In Farwaneh, Samira \& Ouali, Hamid (eds.), Perspectives on Arabic Linguistics XXIV-XXV, 3-19. Texas and Arizona, United States. DOI: https://doi.org/10.1075/sal.1.04dav

de Jong, Kenneth \& Zawaydeh, Bushra Adnan. 2002. Comparing stress, lexical focus, and segmental focus: patterns of variation in Arabic vowel duration. Journal of Phonetics 30. 53-75. DOI: https://doi.org/10.1006/jpho.2001.0151

Eefting, Wieke. 1991. The effect of "information value" and "accentuation" on the duration of Dutch words, syllables, and segments. Journal of the Acoustical Society of America 89(1). 412-424. DOI: https://doi.org/10.1121/1.400475

Goldman, Jean-Philippe. 2011. EasyAlign: an automatic phonetic alignment tool under Praat. In Proceedings of InterSpeech. Firenze, Italy. DOI: https://doi.org/10.21437/Interspeech.2011-815

Goldman, Jean-Philippe \& Schwab, Sandra. 2014. Easyalign Spanish: An (Semi-)Automatic Segmentation Tool Under Praat. DOI: https://doi.org/10.5167/uzh-107124

Gordon, Matthew J. 2002. A phonetically driven account of syllable weight. Language 78(1). 51-80. DOI: https://doi.org/10.1353/lan.2002.0020

Gordon, Matthew J. 2005. A perceptually-driven account of onset-sensitive stress. Natural Language and Linguistic Theory 23(3). 595-653. DOI: https://doi.org/10.1007/s11049-004-8874-9 
Haddad, Ghassan F. 1984. Problems and Issues in the Phonology of Lebanese Arabic. Doctoral Dissertation, University of Illinois at Urbana-Champaign, Illinois.

Hall, Nancy. 2013. Acoustic differences between lexical and epenthetic vowels in Lebanese Arabic. Journal of Phonetics 41(2). 133-143. DOI: https://doi.org/10.1016/j.wocn.2012.12.001

Hall, Nancy. 2017. Phonetic neutralization in Palestinian Arabic vowel shortening, with implications for lexical organization. Glossa: a journal of general linguistics 2(1). 48. 1-23. DOI: https://doi.org/10.5334/gjgl.257

Ham, William. 1998. Phonetic and Phonological Aspects of Geminate Timing. Doctoral Dissertation, Cornell University, Cornell, USA.

Hansen, Benjamin B. 2003. Production of Persian geminate stops: Effects of varying speaking rate. In Agwuele, Augustine \& Warren, Willis \& Park, Sang-Hoon (eds.), Texas Linguistics Society Conference, 86-95. Somerville, MA: Cascadilla Proceedings Project.

Hayes, Bruce. 1989. Compensatory lengthening in moraic phonology. Linguistic Inquiry 20. 253306.

Hellmuth, Sam. 2011. Acoustic cues to focus and givenness in Egyptian Arabic. In Majeed Hassan, Zeki \& Heselwood, Barry (eds.), Instrumental Studies in Arabic Phonetics, 299-324. Amsterdam: John Benjamins. DOI: https://doi.org/10.1075/cilt.319.14hel

House, Arthur S. 1961. On vowel duration in English. Journal of the Acoustical Society of America 33. 1174-1178. DOI: https://doi.org/10.1121/1.1908941

House, Arthur S. \& Fairbanks, Grant. 1953. The influence of consonant environment upon the secondary acoustical characteristics of vowels. Journal of the Acoustical Society of America 25. 105-113. DOI: https://doi.org/10.1121/1.1906982

Hubbard, Kathleen. 1993. Mapping phonological structure to phonetic timing: moras and duration in two Bantu languages. Berkeley Linguistics Society 19. 182-192. DOI: https://doi.org/10.3765/ bls.v19i1.1514

Hyman, Larry. 1985. A theory of phonological weight. Dordrecht: Foris. DOI: https://doi. org/10.1515/9783110854794

Idemaru, Kaori \& Guion, Susan. 2008. Acoustic covariants of length contrast in Japanese stops. Journal of the International Phonetic Association 38(2). 167-186. DOI: https://doi.org/10.1017/ S0025100308003459

Jongman, Allard. 1998. Effects of vowel length and syllable structure on segment duration in Dutch. Phonetics 26(3). 207-222. DOI: https://doi.org/10.1006/jpho.1998.0075

Katz, Jonah \& Selkirk, Elisabeth. 2011. Contrastive focus vs. discourse-new: Evidence from phonetic prominence in English. Language 87. 771-816. DOI: https://doi.org/10.1353/ lan.2011.0076

Kelly, Niamh E. 2021. Phrase-final lengthening across segments in Lebanese Arabic. Proceedings of Meetings on Acoustics 42(1). DOI: https://doi.org/10.1121/2.0001385

Kelly, Niamh E. \& Smiljanić, Rajka. 2017. The Effect of Focus and Phrase Position on East Norwegian Lexical Tonal Accents. Phonetica 74(4). 193-230. DOI: https://doi.org/10.1159/000453270 
Kenstowicz, Michael. 1970. On the Notation of Vowel Length in Lithuanian. Papers in Linguistics 3(1). 73-113. DOI: https://doi.org/10.1080/08351817009389141

Khattab, Ghada. 2002. Sociolinguistic competence and the bilingual's adoption of phonetic variants: Auditory and instrumental data from English-Arabic bilinguals. Doctoral Dissertation, University of Leeds, Leeds, UK.

Khattab, Ghada \& Al-Tamimi, Jalal. 2014. Geminate timing in Lebanese Arabic: the relationship between phonetic timing and phonological structure. Laboratory Phonology 5(2). 231-269. DOI: https://doi.org/10.1515/lp-2014-0009

Kiparsky, Paul. 2003. Syllables and moras in Arabic. In Féry, Caroline \& van de Vijver, Ruben (eds.), The Syllable in Optimality Theory, 147-182. Cambridge: Cambridge University Press. DOI: https://doi.org/10.1017/CBO9780511497926.007

Kuznetsova, Alexandra \& Brockhoff, Per B. \& Christensen, Rune H. B. 2017. lmerTest Package: Tests in Linear Mixed Effects Models. Journal of Statistical Software 82(13). 1-26. DOI: https:// doi.org/10.18637/jss.v082.i13

Lennes, Mietta. 2017. SpeCT - Speech Corpus Toolkit for Praat (v1.0.0). First release on GitHub. DOI: https://doi.org/10.5281/zenodo.375923

Lenth, Russell. 2019. emmeans: Estimated Marginal Means, aka Least-Squares Means. URL: https://CRAN.R-project.org/package $=$ emmeans

Lowenstamm, Jean. 1996. CV as the only syllable type. In Durand, Jacques \& Laks, Bernard (eds.), Current trends in Phonology: Models and Methods, 419-441. Manchester, Salford.

Maddieson, Ian. 1997. Phonetic Universals. In Laver, John \& Hardcastle, William J. (eds.), The handbook of phonetic sciences, 619-639. Oxford: Blackwell.

Mai, Anna. 2020. Phonetic effects of onset complexity on the English syllable. Journal of the Association for Laboratory Phonology 11(1): 4. 1-26. DOI: https://doi.org/10.5334/labphon.148

Makki, Elrabih Massoud. 1983. The Lebanese Dialect of Arabic: Southern region. Doctoral Dissertation, Georgetown University, Washington, D.C.

McCarthy, John. 1979. On stress and syllabification. Linguistic Inquiry 10. 443-466.

McCarthy, John \& Prince, Alan. 1986. Prosodic morphology. (Unpublished manuscript). University of Massachusetts, Amherst and Brandeis University.

Mitleb, Fares M. 1984. Voicing effect on vowel duration is not an absolute universal. Journal of Phonetics 12. 23-27. DOI: https://doi.org/10.1016/S0095-4470(19)30847-2

Nasr, Raja T. 1959. The predictability of stress in Lebanese Arabic. Phonetica 4(2). 89-94. DOI: https://doi.org/10.1159/000257994

Nasr, Raja T. 1960. Phonemic length in Lebanese Arabic. Phonetica 5(3/4). 209-211. DOI: https://doi.org/10.1159/000258058

Niebuhr, Oliver. 2012. At the edge of intonation - The interplay of utterance-final F0 movements and voiceless fricative sounds in German. Phonetica 69(1-2). 7-21. DOI: https://doi. org/10.1159/000343171 
Obégi, Michel. 1971. The Phonemic System of a Lebanese Arabic Dialect. Master's thesis, Simon Fraser University, Burnaby, B.C.

Peterson, Gordon E. \& Lehiste, Ilse. 1960. Duration of syllable nuclei in English. Journal of the Acoustical Society of America 32. 693-703. DOI: https://doi.org/10.1121/1.1908183

Pierrehumbert, Janet. 1980. The phonology and phonetics of English intonation. Doctoral Dissertation, MIT.

Port, Robert \& Dalby, Jonathan \& O’Dell, Michael. 1987. Evidence for mora timing in Japanese. Journal of the Acoustical Society of America 81. 1574-1585. DOI: https://doi.org/10.1121/1.394510

R Development Core Team. 2008. R: A Language and Environment for Statistical Computing. $\mathrm{R}$ Foundation for Statistical Computing, Vienna, Austria. URL: http://www.R-project.org, ISBN 3-900051-07-0.

Rooth, Mats E. 1985. Association with Focus. Doctoral Dissertation, University of Massachusetts, Amherst.

Ryan, Kevin. 2014. Onsets contribute to syllable weight: Statistical evidence from stress and meter. Language 90(2). 309-341. DOI: https://doi.org/10.1353/lan.2014.0029

Sakr, Georges. 2019. A Laboratory Phonology Investigation into the Vocalic Inventory of Lebanese. Master's thesis, University of Edinburgh, Edinburgh, Scotland.

Scheer, Tobias. 2004. A lateral theory of phonology Vol. I. Berlin: Mouton de Gruyter. DOI: https:// doi.org/10.1515/9783110908336

Selkirk, Elisabeth. 1981. Epenthesis and degenerate syllables in Cairene Arabic. In Borer, Hagit \& Aoun, Yosef (eds.), Theoret-ical issues in the grammar of Semitic languages, 111-140. Cambridge: MIT.

Selkirk, Elisabeth. 1984. On the major class features and syllable theory. In Aronoff, Mark \& Oehrle, Richard (eds.), Language Sound Structure, 107-136. Cambridge: MIT Press.

Selkirk, Elisabeth. 2008. Contrastive focus, givenness and the unmarked status of "discoursenew". Acta Linguistica Hungarica 55. 331-346. DOI: https://doi.org/10.1556/ALing.55.2008.34.8

Versteegh, Kees. 1997. The Arabic language. New York: Columbia University Press.

Watson, Janet C. E. 2002. The phonology and morphology of Arabic. Oxford: Oxford University Press.

Watson, Janet C. E. 2007. Syllabification patterns in Arabic dialects: long segments and mora sharing. Phonology 24. 335-356. DOI: https://doi.org/10.1017/S0952675707001224

Watson, Janet C. E. 2011. Word stress in Arabic. In The Blackwell Companion to Phonology, 29903019. Oxford, UK: Wiley-Blackwell. DOI: https://doi.org/10.1002/9781444335262.wbctp0124

$\mathrm{Xu}$, Yi \& Xu, Ching X. 2005. Phonetic realization of focus in English declarative intonation. Journal of Phonetics 33. 159-197. DOI: https://doi.org/10.1016/j.wocn.2004.11.001 